\title{
UNA EXPERIENCIA \\ DE PARTIDO REGIONAL: \\ EL CASO DEL PARTIDO \\ SOCIALISTA DE ANDALUCIA. \\ PARTIDO ANDALUZ
}

Miguel Jerez Mir

\section{INTRODUCCION}

No hace mucho que la opinión dominante entre los estudiosos de la ciencia política, respecto de los movimientos regionalistas y nacionalistas en el seno de las sociedades industriales más 0 menos avanzadas, era la de considerar estos fenómenos como un anacronismo político, al menos en un ámbito europeo occidental que conoció el nacimiento del Estado nacional. En efecto, según los casos, la actitud al uso era la de rechazar abiertamente los grupos de este signo, identificándolos como terroristas, o ridiculizarlos como ejemplo de aventuras estúpidas, las más de las veces inoportunas '. Sólo en la pasada

- Un primer avance de este trabajo fue presentado por el autor como comunicación al III Congreso de la Asociación de Ciencia Política, celebrado en Zaragoza, del 24 al 26 de marzo de 1983. La presente versión corresponde sustancialmente a la entregada al editor en mayo del mismo año, una vez conocidos los resultados de las últimas elecciones celebradas en el ámbito andaluz. 'Aunque luego, en febrero de 1984, ha tenido lugar el V Congreso del PSA, en el que éste adopta la denominación de Partido Andalucista al tiempo que abandona formalmente el socialismo como elemento conformador de su ideología, he creido conveniente no alterar en lo esencial aquella redacción, dado que mi estudio se centra justamente en el período en que esta organización alcanzó a jugar un papel relevante en la escena política española y andaluza.

1 Derek W. Unwin, "Harbinger, Fossil of Fleabite?: the European Mosaic of Regional Parties", en Hans DanLDER y Peter MAIR, Working Papers on Political Parties. El grueso de estos trabajos sería publicado, en 1983, por SAGE, bajo el título de Western European Party Systems. Continuity and Change. Citamos por su versión original, Florencia, 1982 (ejemplar multicopiado), vol. II, pp. 329-330. 
década acusará nuestra ciencia el impacto de tal problemática, incorporando toda una ola de trabajos sobre el tema en respuesta a esa situación por la que estaba pasando gran parte de Europa y que, hace ahora algunos años, el profesor Murillo calificaba de "sarampión regionalista»"

Como es sabido, España no ha escapado al resurgir del fenómeno regional, agudizado entre nosotros por la circunstancia peculiar de haber conocido en los últimos años el paso de un régimen dictatorial, caracterizado en este aspecto por un rígido centralismo político y administrativo y por una inequívoca voluntad uniformadora, a un régimen democrático especialmente sensible hacia las manifestaciones de este signo. Al igual que ocurriera en otros señalados momentos de nuestra historia político-constitucional, en particular con la llegada de la I y II Repúblicas, el tránsito hacia un régimen de libertades viene vinculado al auge de reivindicaciones que van desde el cantonalismo al nacionalismo, pasando por el regionalismo. Si en la etapa previa inmediata a la proclamación de la II República hubo un acuerdo explícito entre los representantes de las distintas fuerzas políticas de oposición al régimen, reconociendo las aspiraciones autonomistas de las diversas regiones del Estado con "personalidad definida" ${ }^{3}$, los últimos años del franquismo y el inicio de la transición conocen un proceso semejante, aunque en esta ocasión aquellas fuerzas convergen en una variopinta diversidad de organismos. Como muestra de lo que afirmamos, bastará un breve repaso de los textos de los documentos más representativos.

- En la Declaración constitutiva de la Junta Democrática de España, fechada en Madrid, el 29 de julio de 1974, se habla de que la oposición política española a la dictadura se ha ejercido desde «plataformas regionales y nacionales», entre otras, propugnando en el noveno de sus doce puntos lo siguiente: «El reconocimiento, bajo la unidad del Estado español, de la personalidad política de los pueblos catalán, vasco, gallego, y de las comunidades regionales, que lo decidan democráticamentem (ejemplar multicopiado, como en los textos que siguen).

2 "La nación y el ámbito de la democracia", Sistema, 26 (septiembre 1978), p. 9.

${ }^{3}$ Nos referimos al acuerdo tomado por las distintas fuerzas republicanas en agosto de 1930, comúnmente conocido como Pacto de San Sebastión. Aunque no existió ningún documento formal, según la referencia que el día 18 de ese mes dio la prensa del país, y según sus consecuencias, cabe deducir que se llegó a un compromiso expreso entre la alianza republicana y la izquierda catalana en el sentido de que, una vez triunfara la revolución, el Gobierno daría una solución jurídica al problema catalán. Esta pasarfa por un Estatuto redactado libremente por Cataluña, sometiéndolo luego al retrendo de las Cortes Constituyentes. Según información publicada en La Vanguardia (19 agosto 1930), "en este espíritu federalista de la Asamblea se dijo también que el mismo criterio habría de seguirse por to que respecta a otras regiones con personalidad definida, como son las Vascongadas, Galicia, etc., dentro de la unión perfecta de todas ellas". Ce. M.' del Carmen GarchNisto y Javier Donzzar, "La Segunda República, economia y aparato del Estado, 1931-1936", en Bases documentales de la España contemporánea, vol. III, Madrid, Guadiana, 1974, pp. 18-19, y 50-51. 
- El «Manifiesto de la Reconciliación», publicado por la Junta Democrática el 1 de abril de 1975, hace referencia en distintos momentos a «los pueblos que componen la comunidad de España» y a las «nacionalidades es. pañolas», reprimidas durante el franquismo mediante la «violencia institucionalizada», llamando a la participación del pueblo en una serie de acciones de RECONCILIACion NACIONAL, entre las que cabe destacar la segunda y la tercera, enunciadas, respectivamente, como sigue: «La Asamblea de Cataluña, la Plataforma unitaria vasca y la Junta Democrática de Galicia son invitadas a concurrir a esta convocatoria con las acciones democráticas peculiares de su identidad nacional, bajo el signo político de la restauración de los estatutos de autonomia dentro del Estado español» (subrayado en el original); «Las Juntas Democráticas regionales son llamadas a convocar también acciones de identidad regional, bajo el signo político de la instauración democrática del Poder regional dentro del Estado español» (subrayado nuestro).

- La Plataforma de Convergencia Democrática, creada en Madrid el 12 de junio de 1975, hacía una doble referencia al tema en su manifiesto: en el punto 2 proclama el establecimiento de un Estado estructurado federalmente, como urio de sus objetivos. El punto 5 es mucho más concreto: «La PCD, consciente de la existencia de nacionalidades con personalidad étnica, histórica o cultural propia en el seno del Estado español, reconoce el derecho de autodeterminación de las mismas y la formación de órganos de autogobierno en las nacionalidades del Estado desde el momento de la ruptura democrática y propugna una estructura federal en la Constitución del Estado español.»

- El «Comunicado constitutivo de Coordinación Democrática» (Madrid, 26 de marzo de 1976), bajo el rótulo «A todos los pueblos de España», hace pública la constitución del nuevo organismo, producto de la disolución simultánea de la Junta Democrática de España y la Plataforma de Convergencia Democrática, encabezadas, respectivamente, por el PCE y el PSOE, e «invita a las instancias de oposición existentes en las nacionalidades y regiones a que se articulen con este organismo en la alternativa democrática a nivel del Estado español».

- Finalmente, el «Comunicado de la Plataforma de Organismos Democráticos» (Madrid, 12 de enero de 1977) afirma en su quinto y penúltimo punto: "La Permanente hace suyas las propuestas de la Taula de Forces Politiques y Sindicals del País Valenciá y de la Taboa Democrática de Galicia para realizar una campaña política en favor de los estatutos de autonomía sin exclusiones...»

Hay, pues, un claro protagonismo de distintas fuerzas regionales y un reconocimiento, por parte de las instancias aglutinadoras de la oposición, de la personalidad política de determinadas regiones, con un paralelo apoyo a los estatutos de autonomía. Podrá observarse, sin embargo, que las únicas referencias expresas a regiones concretas $\mathrm{u}$ organismos de ámbito regional son las que se hacen a Cataluña, Vascongadas y Galicia, y en una ocasión 
al País Valenciá. El resto son referencias genéricas, abiertas, eso sí, a otras "comunidades regionales», a estatutos de autonomía «sin exclusiones», etc. Por otra parte, cualquier observador de la realidad española de aquellos años recordará cómo en las movilizaciones populares antifranquistas y en favor del restablecimiento de las libertades, amnistía, etc., se hizo uso abundante de símbolos de identificación nacionalista y regionalista, algo especialmente evidente en el generoso despliegue de banderas, alguna vez con trágicos resultados. No deja de resultar significativo, en cuanto revelador de las amplias simpatías despertadas entonces por este género de sentimientos, el que la práctica corriente de enarbolar enseñas de otros ámbitos geográficos despertase las más cálidas adhesiones en muestra de solidaridad. Consecuencia de todo ésto es que el advenimiento de la democracia es inevitablemente percibido por gran parte de la población y de los medios de comunicación de masas como vinculado al tema regional. De esta forma, un fenómeno que tuvo su origen en el País Vasco y Cataluña, los dos grandes contenciosos que han mantenido nuestro Estado en las dos últimas centurias, acabó extendiéndose, en urıa u otra medida, al resto de las regiones, circunstancia a la que no fue ajena la propia política de una UCD que, al abrirse el proceso constituyente, optó por aplicar la fórmula gráficamente definida por la expresión «café para todos». Mucho se ha especulado sobre las motivaciones de esta decisión, tomada con el aparente beneplácito de las fuerzas políticas de izquierda. Fuese con el propósito de que, presentada así la cuestión, se venciera más fácilmente la susceptibilidad y eventual oposición de las Fuerzas Armadas a una solución para Cataluña y el País Vasco, fuese por no herir los sentimientos de otras regiones o por cualesquiera otras razones, lo cierto es que esta política contribuyó decisivamente a alimentar reivindicaciones y a despertar expectativas autonomistas en todo el ámbito del territorio español.

Como es notorio, el brote de esta suerte de sentimientos y reivindicaciones durante la transición democrática ha conocido una fuerza singular en Andalucía, hoy por hoy, el área del país a la que corresponde mayor número de escaños en las Cortes y la segunda en cuanto a electores, después de Cataluña. Pues bien, en ese resurgir $\longrightarrow$ simplemente surgir, según las interpretaciones - del andalucismo iba a jugar un papel clave una formación política particularmente joven, el Partido Socialista de Andalucía (PSA).

No hace mucho que el profesor Maravall, escribiendo sobre la transición, subrayaba el hecho de que en España se ha infravalorado la importancia política de los partidos nacionalistas. La observación es perfectamente válida para el caso andaluz. Y tuvo sus efectos políticos -me atrevería a decir que incluso constitucionales, por su repercusión sobre la ordenación de nuestro ordenamiento en el terreno autonómico- y, desde luego, sus costos electorales para determinados partidos. Al parecer, ha debido tener también algún costo en el campo de la investigación, pues —que sepamos- 
aún no se cuenta con ningún estudio monográfico sobre un partido, el PSA, que se proclama oficialmente nacionalista en enero de 1979.

Entiendo que sobran motivos para justificar cualquier aproximación a la realidad política andaluza a la hora de reflexionar sobre la transición. Baste recordar, además del aludido potencial electoral, que el referéndum del 28 de febrero de 1980 es el primer gran descalabro del entonces partido en el Gobierno (al mes siguiente vendrían las esperadas derrotas de UCD en las elecciones a los Parlamentos catalán y vasco); y que tanto el debate sobre la moción de censura conio el de la cuestión de confianza giraron en muchos momentos sobre el tema andaluz, como comprobará cualquiera que se asome a lás páginas del Diario de Sesiones ${ }^{+}$o simplemente a la prensa de aquellos días. Por otra parte, es en las elecciones al Parlamento de Andalucía, en mayo de 1982, donde la UCD sufre la primera derrota por su izquierda y la segunda a manos de AP, resultado que da lugar al primer Gobierno socialista que conoce el país desde 1939 y prefigura la nueva correlación parlameritaria surgida de las elecciones de octubre.

En lo que hace al interés de un estudio acerca del PSA puede mencionarsє, sobre lo ya dicho, lo novedoso de un partido regional que, definiéndose como socialista y nacionalista, alcanza una representación parlamentaria relativamente amplia — cinco diputados en 1979, a los que se agregarían otros dos durante el curso de la legislatura, procedentes de UCD y PSC/PSOEeri un territorio que, si en nuestro reciente pasado histórico no había destacado precisamente por sus sentimientos autonomistas, quedaba ahora como la tercera región del país en índice de regionalismo/nacionalismo. Y el que con ello se convirtiera en el artífice de uno de los dos retrocesos electorales más significativos sufridos por el PSOE en una región considerada tradicionalmente feudo socialista (como se recordará, el otro fue el experimentado en el País Vasco en favor de Herri Batasuna, aunque aquí la abstención jugaría un papel especialmente relevante). No sin razón, ha podido afirmarse que, junto con el lanzamiento del «invento» UCD por Adolfo Suárez. la operación política del PSA constituye uno de los fenómenos más sorprendentes de la transición, siendo quizá el tercero a citar el éxito electoral de la citada coalición abertzale.

Todo esto ha podido tener, siquiera sea transitoriamente, una incidencia en la configuración de un sistema político regional específicamente andaluz, dotado de una particularidad política propia que le haría moverse en distinta dirección que la del resto del país, como apuntara López Guerra ${ }^{5}$ De la

- Véase D.S.C., núms. 94 y 95 , de 20 y 30 de mayo de 1980 , pp. 6132-6138, 6159 y ss., 6245-6250 y 6282 (para la moción de censura), y núms. 110 y 111, de 16,17 y 18 de septiembre, pp. 7079-7211, passim (para la cuestión de confianza). El mismo Felipe González afirmaría durante su intervención en el segundo debate: "Hemos estado muy metidos en la polémica andaluza" (p. 7186).

s Jorge de Esteban y Luis López Gurran, Las elecciones legislativas de 1 de marzo de 1979, Madrid, Centro de Investigaciones Sociológicas, 1979, pp. 514-515 y 519. 
misma manera, los últimos fracasos electorales del PSA han supuesto sin duda, desde el punto de vista del sistema de partidos, un amortiguamiento de las diferencias regionales, al debilitarse un factor que cabría caliticar de centrífugo ${ }^{6}$. Dicho en otros términos, con ello tendía a desaparecer uno de los elementos conformadores del pluralismo segmentado en España ${ }^{7}$. Pero es que, además, el PSA ha tenido un protagonismo político por encima del que pudiera indicar su número de diputados, en el doble ámbito constitucional y parlamentario. En el primero incidiendo decisivamente en el rumbo que iba a llevar el Estatuto de Andalucía ${ }^{8}$, que en cierto modo quebraría el proyecto autonómico del título VIII tal como fue concebido por los constituyentes. $\mathrm{Y}$ en el segundo, haciendo posible mediante su apoyo, sumado al de la Minoría Catalana. una mínima estabilidad gubernamental, tras la quiebra del consenso entre UCD y el PSOE".

Finalmente, resulta indiscutible que el PSA alcanzó a cubrir satisfactoriamente, en el período 1977-1979, las tres actividades electorales que deben concurrir a la hora de diferenciar un partido sobre una base regional ${ }^{10}$ : a) la capacidad para presentar candidatos dentro de la región; b) su habilidad para ganar votos (en un par de provincias - Granada y Almería- los gana incluso en las elecciones locales respecto a las generales de 1979, en términos proporcionales; y c) su capacidad para obtener representación desde una región en las cámaras legislativas a nivel nacional.

Movido por las anteriores consideraciones, pretendo abordar ahora, de un lado, el proceso de configuración del PSA, así como la identificación y análisis de los componentes que conformaron su ideología. De otro lado, ensayo una caracterización del partido en base a una serie de variables sociopolíticas, para examinar finalmente su evolución electoral desde 1977.

\section{PROCESO DE CONFIGURACIQN DEL PARTIDO}

\section{Fundación y época testimonial}

El Partido Socialista de Andalucía tiene su origen más inmediato en el Congreso de la Alianza Socialista de Andalucía (ASA), inaugurado el 25 de julio de 1976, en Málaga. El primer punto del orden del día era justamente la presentación al Congreso de una propuesta de la Comisión Permanente de

- Cf. Manuel Ramírez, "Aproximación al sistema de partidos en España (19311981)", en Estudios sobre Historia de España, Madrid, Universidad Internacionaí Menéndez Pelayo, 1981, vol. 2, p. 225.

Cf. José M. Maravall, "Transición a la democracia. Alineamientos políticos y elecciones en España", Sistema, 36 (mayo 1980), p. 96.

${ }^{8}$ Véase A. Porras Nadales, "El referéndum de iniciativa autonómica del 28 de febrero en Andalucía", $R E P$, núm. 15 (mayo-junio 1980), pp. 177 y ss.

"J. LiNz, "La frontera sur de Europa", REIS, núm. 9 (enero 1980), y Manuel RAMfREz, loc. cit., p. 225.

${ }^{10}$ Derek W. URWIN, cit., p. 338. 
ASA, fechada en Ecija, donde estuvo confinado Alejandro Rojas Marcos, a la sazón miembro de la secretaría general, el día 4 de ese mismo mes. Se trataba de someter a debate y posterior votación la conversión de la organización en partido político, argumentando que «objetivamente se dan las circurstancias que hacen ya necesario un partido de exclusiva soberanía andaluza y con el carácter socialista que impone la condición del pueblo andaluz». Las propuestas concretas eran las siguientes:

1. La transformación de Alianza Socialista de Andalucía en partido político de ámbito regional, articulado a nivel del Estado español en la Federación de Partidos Socialistas, que adopta a partir de este momento el nombre de Partido Socialista de Andalucía.

2. La apertura de un proceso constituyente que configure el Partido, quedando abierto al Congreso mientras dure este proceso, lo que aparecerá indicado de la siguiente manera: «Partido Socialista de Andalucía (en proceso constituyente)».

3. Las invitaciones a integrarse y participar en este congreso constituyente a todos los sccialistas de Andalucía, y muy especialmente a Reconstrucción Socialista de Andalucía, con quien se mantiens un proceso de convergencia ".

El 92 por 100 de los votos de los compromisarios fue favorable a la conversión en partido de esta organización ${ }^{12}$ fundada en Sevilla, en noviembre de 1973, como una alianza de "grupos de compromiso político", sobre la base de su interinidad: "Nacen con ocasión de la dictadura y morirán con ella», se afirma en su manifiesto fundación ${ }^{13}$. A su vez, ASA recogía la experiencia de los "grupos de Compromiso Político", formalizados como CP, SA, en 1966, y que actuaron con anterioridad sin estructura orgánica en el ámbito de la Baja Andalucía, mediante acciones políticas y cívicas que se remontan a un núcleo originario de Sevilla, a parrir de $1965^{14}$.

El Congreso, que se celebraba al mes siguiente del primero organizado a la luz pública en España por un partido socialista (el III Congreso del PSP). contó con la asistencia de más de mil personas, entre militantes de ASA,

"Congreso Alianza Socialista, Mrálaga, 25 de julio de 1976 cejemplar inulticopiado).

${ }_{12}$ Agencia Cifra, Málaga, 26 de julio de 1976.

${ }^{3}$ "Los grupos de compromiso político deberán ser conscientes de su interinidad: son indispensables hoy porque los partidos políticos tradicionales no bastan... Ahora bien, al término de la dictadura, tantos hombres que hoy luchan en esos grupos buscarán la integración en los partidos políticos que surjan a la legalidad democrática en ese momento", Alianza Socialista de Andalucía, "Manifiesto fundacional", Cuadernos del Ruedo Ibérico, 41-42 (febrero-mayo 1973), pp. 95 y ss.

${ }_{14}$ Entre estas actuaciones pueden mencionarse la iniciativa de respaldar a Rojas Marcos en las elecciones municipales de 1966, en Sevilla, o la intervención en el sonado proceso de democratización de El Correo de Andalucía. Cf. Vargas MAchUcA, "Sobre la historia del PSA", Andalucía Libre, Epoca II, núm. 2 (febrero 1978), y A. Checa Godoy, Las elecciones de 1977 en Andalucía, Granada, 1978. pp. 13-14. 
«Reconstrucción Socialista», socialistas independientes y representantes de todas las organizaciones políticas y sindicales a nivel regional y nacional, a excepción del PSOE (si bien había algún miembro de este partido, no lo estaba oficialmente) ${ }^{15}$. Como es sabido, la fundación del PSA a raíz de este congreso constituyente fue recibida con desigual contento. Así, mientras la Federación de Partidos Socialistas (FPS) se apresuró lógicamente a saludar la creación del partido, afirmando que «no se puede asimilar un proceso político abierto y público, de convergencia de colectivos socialistas, con una mera táctica de aprobación de un nombre», la reacción del PSOE y del Movimiento Socialista Andaluz (MSA) fue radicalmente opuesta. El primero, a través del Comité Regional de Andalucía había hecho público, el mismo día 25, en el Correo de Andalucía, de Sevilla, un comunicado en el que denunciaba la decisión de constituir el Partido Socialista Andaluz, acusando a ASA de oportunismo político y de intentar acaparar las opciones socialistas de los andaluces, motivo, entre otros, por el que había rechazado la invitación para asistir al Congreso ${ }^{16}$. Por su parte, el Comité ejecutivo del MSA, reunido en Casares (Málaga), coincidía en calificar de acto meramente oportunista la "pretendida creación del Partido Socialista Andaluz», estimando que ello sólo podría conducir «al confusionismo entre los andaluces, que ni están encuadrados en dicho colectivo ni se pueden sentir solidarios con dicho tipo de maniobra» ${ }^{17}$.

Aunque no hemos hecho registrado reacciones iniciales por parte del PCE, lo lógico es que viera con agrado la formalización de un partido que podía restar votos en Andalucía a su principal competidor en la izquierda, el PSOE, en las más que previsibles elecciones (el Gobierno Suárez acababa de prometerlas en su declaración programática de hacía poco más de una semana, para antes del 30 de junio de 1977). En cuanto a la derecha que estaba por el restablecimiento de las libertades, en principio parece normal que encontrara también motivos de satisfacción en algo que introducía un nuevo elemento de fragmentación del campo socialista y que, a la hora de las elecciones, supondría una división del voto de este signo, por lo menos en Andalucía (el proyecto de estatutos del PSA presentado al congreso de Málaga hablaba, en su artículo 14, de la «novena provincia»-la emigrante-,

${ }^{15}$ Ideal, de Granada, 27 de julio de 1976.

10 Ideal, 27 de julio de 1976. En este comunicado se subrayaba el carácter de "fuerza predominante", en el seno del socialismo andaluz, de las Federaciones provinciales integradas en el Comité, para finalizar estableciendo un paralelismo entre la constitución del PSA y la maniobra protagonizada por el grupo socialdemocrático de Palach, al constituirse en Partido Socialista Catalán, "ignorando a la mayoría de los socialistas catalanes, operación que fue denunciada en su día, tanto por el PSOE como por la Federación de Partidos Socialistas de la que forma parte la propia ASA".

${ }_{17}$ Ideal, 27 de julio de 1976. Este partido había surgido en Málaga a principios de año en torno a un antiguo miembro del PSP, el abogado Primitivo de la Quintana. Presentaria candidaturas en cuatro provincias con pobres resultados. A. Creca, Las elecciones de 1977 en Andalucía, Granada, Aljibe, 1978, p. 14. 
aludiendo fundamentalmente a Barcelona y Madrid, si bien no de modo explícito). De hecho, y aunque sin duda intervendrían otros factores, el Congreso del PSA se celebró normalmente, mientras que el XXVII Congreso del PSOE que debía tener lugar en Madrid fue prohibido inicialmente por el Gobierno. Esto, a su vez, motivó que la sesión de clausura prevista para cerrar el período constituyente del primero y anunciada para el 24 de octubre, fuese autosuspendida como «acto de protesta» por los dirigentes del PSA ${ }^{18}$.

En el transcurso de dicho proceso constituyente se integraron en el partido, además de un apreciable número de socialistas independientes, Reconstrucción Socialista de Andalucía (lo que supuso la incorporación de Antonio Ibáñez, líder sindical de Cádiz que tuvo importancia en el PSA, sobre todo en el intento de crear un sindicato andaluz) y el Movimiento Autonomista Socialista Andaluz. La sesión de clausura tuvo lugar, finalmente, el 28 de noviembre, en Sevilla. Allí se debatió y aprobó la declaración constitucional, así como los estatutos del nuevo partido. Si la primera explica el modelo de sociedad propugnado -el socialismo autogestionario-, concretando los objetivos y medios para la consecución de un «poder andaluz», los estatutos se centran en la cuestión organizativa.

Sobre el primer tema habrá ocasión de extenderse al tratar de los presupuestos ideológicos del partido. En cuanto a su estructura interna, frente al modelo del centralismo democrático o del "parlamentarismo socialdemócrata», se proclama la opción por la demucracia interna. Tal concepción descansaría en la existencia de un órgano "que, situado entre la dirección y la base, sintetice en todo instante la voluntad soberana del Congreso y fiscalice de manera permanente la ejecución de la líriea del partido marcada por él mismo». Se alude con ello a la Comisión Permanente del Congreso, entendida como «medio de impedir la posible degeneración oligárquica del partido» e integrada por. 33 miembros, elegidos antes de cada Congreso a través de asambleas, con arreglo a dos fases: en una primera las asambleas elegían dos miembros de cada provincia; los restantes eran elegidos en un segundo turno entre candidatos de toda la organización a propuesta de los ya elegidos. Los estatutos dibujaban un organigrama del partido presentado de abajo arriba en tres niveles: organización de base, integrada por un conjunto de "grupos de base» de entre tres y nueve miembros, más las asambleas locales y provinciales; Congreso, con su Comisión Permanente, estando constituido el primero por la reunión de los militantes del partido, y organización de dirección, formada por los comités locales, comités provinciales y el Comité Ejecutivo. Este último, que no consta de un número fijo de miembros, es el máximo órgano dirigente; estatutariamente, debía ser elegido por el Congreso, pero al tener éste carácter constituyente, la elección quedaba para des. pués de que terminara, realizándose a través de las asambleas correspondien.

is El Pais, 20 de octubre de 1976. 
tes. La presidencia, coordinación y representación del Comité Ejecutivo corresponde a la Secretaría General, que, se dice, no puede ser unipersonal. Tan sólo un par de semanas más tarde, quedaba aprobada mediante referéndum la Ley para la Reforma Política. Como se recordará, la oposición democrática quedó dividida entre el sí, la indiferencia y la abstención activa. El PSA se había inclinado en su Congreso por esta última postura, afín a la de Coordinación Democrática, en cuya sección andaluza decidió integrarse ahora (ASA no participó en su momento en Coordinación Democrática de Andalucía por considerarla sucursalista. El Pais, 22-V-1976). La iniciativa del Gobierno Suárez era condenada como contraria a «los intereses de la democracia». Pero la nueva Ley implicaba la celebración de elecciones generales a corto o medio plazo, ante lo cual el partido hará un par de puntualizaciones desde las páginas de Andalucía Libre, su órgano de prensa: a) sólo concurriría si se daban unas «condiciones mínimas», a establecer por la Oposición Democrática; b) las elecciones son consideradas como «una palanca más de la lucha por la libertad, no como deben ser unas elecciones consecuencia de la Libertad». En consecuencia, termina afirmando, «nuestra opción electoral, pasa por la formación de un BLOQUE ANDALUZ, integrado por las fuerzas políticas $\mathrm{y}$ hombres independientes que lleguen al pacto de un programa mínimo en defensa de los intereses del pueblo andaluz» ${ }^{19}$. Como es sabido, el PSA acudiría a la convocatoria del 15 de junio con el Partido Socialista Popular, bajo el nombre de Unidad Socialista. Si bien la coalición obtuvo cerca del 5 por 100 de los votos válidos emitidos en Andalucía, sólo consiguió un escaño - de los 91 correspondientes a la región- en Cádiz (con el 9,78 por 100 de los votos), y éste iría a manos del PSP, con lo que el PSA quedaba conderiado a permanecer al margen de la vida parlamentaria ${ }^{20}$. Tras la fallida experiencia unitaria, el partido acudiría en solitario al resto de las elecciones celebradas en territorio andaluz, al igual que haría en las autonomías catalanas. No obstante, conviene hacer notar que, por espacio de un año, mantuvo lin pacto con el PCE de cara a las elecciones municipa-

19 "Referéndum: otro más", Andalucia Libre, núm. 3 (noviembre 1976), p. 2. Conforme a esa idea de alianza electoral el Congreso había acordado la formación de una comisión de enlace (de alcance regional) con el PSP, produciéndose algunos contactos en enero de 1977. Hacia las mismas fechas tenía lugar una reunión de independientes con el PSA: Plácido Fernández Viagas -más tarde del PSOE y presidente de la Junta de Andalucía-, Alfonso de Cossío, José M.- Javierre, Juan Antonio Lacomba y José R. Moreno discutieron con el partido la estrategia de la oposición andaluza ante las elecciones, acordándose que los independientes se presentarían como tales en las listas del PSA/PSP, en lo que se denominó Frente Electoral Andaluz (véase El Pais, 9 y 11 de enero de 1977).

20 Más tarde, al pasarse el diputado del PSP. Caamaño, al PSOE, el PSA reivindicaría para sí ese escaño $y$, por ende, la condición de partido parlamentario Sirva como muestra el punto I del documento presentado por su Comité Ejecutivo al presidente de la Junta de Andalucía, en el verano de 1978, a pocas fechas de la disolución de la FPS: "El PSA por cuanto se considera partido parlamentario, al haber obtenido un escaño, aunque su titular se haya pasado a otro partido, pide a la Junta participar en las comisiones de trabajo que nombre." 
les, preparando la elaboración conjunta de un proceso electoral municipal, que incluía programas y candidaturas comunes. El llamado «Pacto Andaluz para unos Ayuntamientos democráticos» surgió con motivo de la presentación por el Gobierno Suárez del proyecto de ley de elecciones locales, que ambos partidos coincidieron en considerarlo contrario a sus intereses, calificándolo de antidemocrático ${ }^{21}$. Pero el compromiso fue roto por acuerdo del Comité Ejecutivo del PSA, en diciembre de 1978, aduciendo que las condiciones políticas eran muy otras tras $\epsilon$ referéndum constitucional, especialmente en lo referente al panoramia autonómico, por lo que convenía que la imagen del partido quedara «nítidamente diferenciada de cualquier otra opción políticas ${ }^{22}$.

En su corta historia como partido, el PSA ha celebrado cuatro congresos, además del fundacional (desapareciendo en el último como tal PSA al transformarse en Partido Andalucista). El II Congreso, al igual que los posteriores, tuvo lugar en Sevilla. Aunque anunciado para los días 7 al 9 de julio de $1978^{23}$, no llegó a reunirse trasta la segundá semana de enero, es decir, poco después de promulgarse la Constitución y cuando el país se encuentra en la antesala de una doble convocaroria electoral, a Cortes ordinarias y a los entes locales. En el ínterin entre congresos se había unido al partido la «Junta Liberalista de Andalucía», fundada en Ronda por Blas Infante, en 1918, hecho que venía a subrayar el carácter andalucistá del PSA, a otorgarle «la legitimidad histórica del andalucismo», en expresión empleada por su secretario general, Alejandro Rojas-Marcos, en su priniera intervención en el Congreso de los Diputados ${ }^{24}$. La integración fue anunciada por el último presidente de la Junta, Juan Alvarez-Assorio, en un comunicado fechado en Sevilla, el 14 de abril de $1978^{25}$, y corisumada el 21 de mayo siguiente, en Ronda. Precisamente este segundo cónclave sería presentado por Andalucía Libre como «el Congreso del Andalucismo» ${ }^{25}$. La propia Declaración del Congreso señala comio tarea fundamental de éste, en el plano teórico, «el análisis y la definición del riacionalismio andaluz, profundizando en él, atendiendo tanto a la realidad política como, y fundamentalmente, a los avances del propio partido en su maduración teórica y en su práctica política». En este mismo sentido, resulta significativo que la declaración incorpore como título de un

"Andalucía Libre, Epoca II, núm. 2 (febrero 1978).

22 "A las elecciones, sólos", Andalucía Libre, Epoca II, núm. 9 (noviembre-diciembre 1978), p. 1.

33 Andalucía Libre, Epoca II, núm. 4 (mayo 1978), p. 1.

24 Diario de Sesiones, 30 de marzo de 1979 , p. 840 . Hay que señalar que el órgano portavoz del PSA, Andalucía Libre, había tomado el nombre, ya en 1976, del órgano de la que fuera la más característica publicación de la Junta Liberalista de Andalucía y primer órgano de expresión anarco-andalucista. Cf. José Acosta. Andalucía de una identidad y la lucha contra el centralismo, Barcelona, Anagrama, 1978, p. 232.

${ }_{25}$ "Por qué nos unimos al PSA", Andalucía Libre, Epoca II, núm. 5 (junio de 1978).

26 Número 11 (febrero 1979). 
apartado específico la expresión «Partido Socialista de Andalucía, Partido Andaluz», anunciando la nueva combinación de siglas con la que iba a acudir a las inminentes elecciones. En cuanto «proyección del andalucismo», el Congreso abordó lo que se calificaría como aspectos fundamentales definidores de la política del partido: la política del Estado en el marco del nuevo texto constitucional, con especial atención al tema autonómico; la política municipal; las relaciones con otros pueblos del mundo; y la política sindical.

No menos sintomático del desplazamiento ideológico iniciado me parece el hecho de la desaparición de un tema que abría la declaración del anterior Congreso: el rechazo explícito de la sociedad y del sistema capitalista. La cuestión era desarrollada entonces con cierto detenimiento, en sus niveles económico, social, político e ideológico-cultural. Ahora se omite el propio término «marxismo» y todo queda en una vaga referencia por la que el partido "reafirma las bases mínimas de coincidencia ideológica aprobadas por el I Congreso" y recogidas en la mencionada declaración, que, como veremos al analizar la ideología, sí incluían puntos como el «marxismo crítico» y la lucha de clases. Precisamente una propuesta de algún sector del Congreso en el sentido de potenciar esta última idea, y de incluir aquel término en contra de la postura de Rojas Marcos, había sido el tema que suscitó mavor controversia a lo largo de las sesiones.

En otro orden de cosas, cabe señalar algunas diferencias con el primer congreso, que van desde el ambiente hasta la duración y lugar, pasando por el sistema de representación: a) no se invita ya a los partidos más o menos afines que la evolución política del país había convertido en rivales, aunque sí a otros partidos regionales como Pueblo Canario Unido, Unión do Pobo Gallego, Partido Socialista de Aragón y PNV, todos los cuales enviaron su adhesión; a la coalición Euskadiko Ezkerra, que estuvo representada por el ex senador Juan María Bandrés; y, sobre todo, a partidos amigos del extranjero, siendo especialmente nutrida la representación del mundo árabe ${ }^{27}$; b) se adopta el sistema de delegados, que sumarían 333, mientras que en la anterior ocasión todos los militantes pudieron tomar parte en la asamblea, con derecho a voto (junto a la desaparición de la novena provincia, debido a los problemas de representación, ésta sería la única modificación de interés introducida en el aspecto organizativo de los estatutos); c) existencia de ciertas tensiones, ausentes en el momento fundacional, presentadas por la prensa del partido como «la inevitable y enriquecedora dialéctica direcciónbase que debe darse en todo partido»; y d) un dato simbólico: si la apertura del primer congreso tuvo lugar en un marco universitario, el Paraninfo de

${ }^{27}$ Asistieron representantes del Congreso General del Pueblo Libio, Partido Socialista Baath de Siria, Partido Socialista Baath de Irak, USFP de Marruecos y de la OLP, así como de la Unión Democrática Bretona y del Pasok; y enviaron su adhesión el Partido Nacionalista de Escocia y Gales, Frente de Liberación Nacional de Argelia, y Maurizio Xiberras, líder de la oposición gibraltareña, Andalucía Libre, núm. 11, p. 4. 
la Universidad malagueña, y su clausura, meses más tarde, en un cine de una barriada sevillana; el segundo se realizó íntegramente, durante tres días consecutivos, en uno de los mejores hoteles de la ciudad del Guadalquivir. El cambio de escenario era interpretado desde las páginas de Andalucia Libre, no tanto como un signo de «aburguesamiento», sino como de «haber pasado el sarampión propio de un joven partido de izquierdas» y de «saber afrontar con realismo las necesidades y las finalidades del partido». Lo que en todo caso evidenciaba era una sensible mejora de los recursos de la organización, tema sobre el que, especialmente tras su éxito electoral del 1 de marzo de 1979, se harían todo tipo de especulaciones (como se recordará, las más difundidas conectaban, ora con Gadafi, ora con las arcas de UCD).

\section{Etapa institucional y crisis}

Con dicho triunfo, que analizaremos con mayor detalle al hablar de su trayectoria electoral, el PSA-PA parecía consolidarse como partido, iniciando ahora su etapa institucional en la faceta parlamentaria y dejando atrás la época testimonial. El Comité Ejecutivo, ahora denominado «Comité Nacional», aprobaría por unanimidad la decisión de que los diputados del partido votaran a favor de Suárez en la investidura, a cambio de obtener grupo parlamentario propio. El tema tampoco planteó mayor controversia entre los cuadros dirigentes o entre los militantes de base que aceptaron, con mayor o menor entusiasmo, la estrategia de respaldo inicial a la UCD, una vez que les fueron explicadas las notorias ventajas de la contrapartida obtenida, insistiéndose en que la voz de Andalucía se oiría en adelante en el Congreso en las mejores condiciones reglamentarias, al disponer los andalucistas de los mismos turnos y tiempos que los grupos «centralistas». Incluso el electorado del PSA pudo entender en un principio estas razones, como parece evidenciar el hecho de que no haya un descenso sustancial de sus votos en las municipales, celebradas poco después.

Sin embargo, no tardarían en surgir los primeros problemas serios de cohesión interna con motivo del rumbo final de las negociaciones con el PSOE y el PCE para la distribución de las alcaldías en Andalucía, tras las elecciones de abril. El acuerdo del comité andalucista fue el de exigir en esas negociaciones las alcaldías de Granada y Huelva, àsí como la Consejería de Cultura, a cambio de sus votos en favor del PSOE para la de Sevilla. La Comisión Permanente respaldó esta decisión, acordando que no se cambiase ninguna alcaldía por la de Sevilla, cuando nadie podía pensar que ésta iba a serle ofrecida al PSA. Pero, al parecer, Arredonda, Rojas Marcos y Uruñuela estaban ya negociando subrepticiamente el tema, sin olvidar a la UCD en gestiones. A la hora de adjudicar las alcaldías, la comisión negociadora optó por el método de ir cerrando casos, desde los pueblos, donde no hubo mayores problemas, hasta las ciudades y capitales de provincia. PSOE y PCE 
estaban dispuestos, en principio, a aceptar las demandas del PSA, pero en el último momento se propondría el canje de Huelva y Granada por Sevilla. Rodríguez de la Borbolla, en representación del PSOE, anunció que aceptarían dejar Sevilla al PSA siempre que las demás capitales en litigio quedaran para su partido, siendo Córdoba para el PCE. Y así se haría finalmente: dado lo avanzado de la hora - tres de la madrugada del último día - a los andalucistas de las ciudades afectadas, consultados telefónicamente, sólo les quedaba negarse al canje, lo que suponía salirse de la negociación y abrir la crisis en el partido al contradecir al secretario general, o aceptar esta solución (testimonio de Pedro Ruiz Morcillo, miembro de la comisión negociadora en representación del PSA). Pero la sensación de malestar quedaba ya sembrada entre los litigantes y en el electorado de Granada y Huelva, como se demostraría más tarde. En efecto, si la imagen del partido pudo deteriorarse en el curso de las negociaciones debido al coqueteo con UCD, el acuerdo finalmente adoptado le granjeaba un sambenito muy peligroso en términos electorales y de cohesión interna: me refiero, claro está, a las acusaciones de centralismo sevillano. Preconcebida o no en su justo alcance, ésta resultó ser una auténtica jugada maestra de los dirigentes del PSOE en Andalucía, que, al igual que los representantes de otros partidos de ámbito estatal, tenían servida una cómoda respuesta a los ataques del PSA denunciando el centralismo madrileño.

El segundo momento crítico tiene lugar en mayo de 1980 con la moción de censura. Aunque el PSA se sumó al grueso de los grupos parlamentarios al votar afirmativamente la moción, su Comité Ejecutivo tuvo que vencer previamente la resistencia del secretario general, que estaba por la abstención (pese a la responsabilidad del partido del Gobierno en el escandaloso plan. teamiento del cercano referéndum del 28-F), aplicando su peculiar tesis de la necesidad de mantener un «hilo conductor» con la UCD, sobre la base del razonamiento siguiente: puesto que el PSOE no tenía la menor simpatía hacia el PSA, éste no debía enfrentarse abiertamente con la UCD, pues, de granjearse su enemistad, el partido se encontrarían entre dos fuegos. El propio texto de la intervención de Rojas Marcos en el debate experimentó algunas modificaciones, sin que quedase claro hasta el último momento cuál iba a ser el sentido del voto de su grupo. Pero será a raíz del planteamiento de la cuestión de confianza, a final del verano, cuando se abrirá definitivamente la crisis interna del partido. Rojas Marcos había estado negociando con la UCD el desbloqueo del proceso autonómico andaluz. Por su parte, el Comité Ejecutivo del PSA, en dos reuniones sucesivas celebradas en septiembre sin la presencia del secretario general, acordó que el partido se pronunciara negativamente. Sin embargo, Rojas se impondría al Comité, tras. ladado a Madrid para discutir el tema, afirmando que la negociación había cambiado y que era preciso votar afirmativamente; la UCD ofrecía la vía del 144 y él tomaba esta decisión personal como portavoz del grupo parlamentario, haciéndose responsable de la estrategia del partido. 
Así se haría finalmente ante el desconcierto de más de un parlamentario del propio grupo andalucista. Esta vez se había ido demasiado lejos, pues resultaba sumamente difícil encontrar razones para justificar no ya ante el electorado andaluz, sino ante los propios militantes del partido, el nuevo «maridaje» con una UCD cuya imagen había quedado sumamente maltrecha a raíz del 28-F. El mismo Comité Nacional se encontraba seriamente dividiclo. Los más descontentos -Ladislao Lara, Pedro Ruiz Morcillo (secretario de Huelva y de Estudios e Información, respectivamente, y ambos granadinos) y Antonio Ibáñez (secretario de Acción Política) - ya a primeros de septiembre habían mantenido una reunión, previa a las dos mencionadas del ejecutivo, con González Ceballos (secretario de Organización y Acción Sindical), considerado hasta entonces el hombre de Alejandro en el partido. Ahora los críticos exigían de Rojas Marcos la sustitución del secretariado de consulta con el que venía operando - eligiendo él a sus miembros personalmente, por «funciones» y no según un criterio territorial- por un secretariado elegido, más reducido. En definitiva, el apoyo al líder quedaba condicionado a que devolviese el poder con el fin de corregir su estrategia populista y ambigua. Pero, tras algunos intentos de negociación, aquél reaccionaría convocando en octubre al Comité Nacional, ante el que planteó la necesidad de aplicar sanciones por falta de disciplina grave. La Comisión Permanente, reunida al efecto, se declara incompetente y convoca a su vez un congreso extraordinario para el 14 de diciembre, con la finalidad de solucionar el enfrentamiento en el seno del comité. Entre tanto Rojas Marcos confiaba en que las elecciones parciales al Senado, que se habían de celebrar en Sevilla y Almería el 18 de noviembre, dieran la victoria al candidato andalucista por la primera provincia, o al menos quedara mejor colocado que en 1979 , lo que equivaldría a un respaldo popular a la estrategia política desplegada por el secretario del partido desde entonces. Pero no fue así: en Sevilla el PSA vería reducidos sus votos a menos de la mitad, lo que suponía no sólo un mayor distaniciamiento respecto a los resultados del PSOE, sino quedar por debajo del candidato comunista - casi 44.000 votos menos-, cuando en la anterior ocasión se había superado al PCA.

Con estos antecedentes se llegará al Congreso extraordinario, con un tema único: la presentación y votación de dos candidaturas, encabezadas, respectivamente, por Rojas Marcos, entonces diputado por Cádiz, y Lara Palma, que había ido al frente de la lista andalucista por Huelva en las legislativas. Triunfaría la corriente oficialista, que obtuvo 198 votos frente a los 136 de la "fraccionalista». Dado que hubo nueve abstenciones, el respaldo obtenido por el líder del partido fue sólo, en términos puramente cuantitativos, del 37,7 por 100 , frente al 39,7 por 100 de los críticos, que además contaron con el voto de siete de los 16 miembros del Ejecutivo (casi el 44 por 100) ${ }^{28}$. Magra diferencia como para consolidar un liderazgo o cerrar una crisis, incluso si se compara con otro partido que a la sazón

28 Andalucia Libre, núm. 33 (enero 1981), p. 8. 
vivía también graves problemas internos, la UCD que pronto iba a celebrar su conflictivo II Congreso ${ }^{29}$, por no mencionar al PCE, dada la particular idiosincracia con que manifestaba su crisis ${ }^{30}$. La consecuencia inmediata de esa votación fue la expulsión de la mayoría de los «fraccionalistas» en el plazo de cuatro días, incluido González Arcas, teniente de alcalde de Granada. La reacción de éstos fue organizar un «bloque de solidaridad», al que se sumaron las organizaciones de Granada y Huelva (completas), gran parte de la provincia de Cádiz, al parecer no muy frecuentada por su diputado Rojas Marcos, y bastantes militantes de Córdoba. Jaén abandonaría enseguida, sin que los disidentes encontraran eco en Málaga y Almería. Paralelamente se formó una coordinadora de los críticos, compuesta por elementos de todas las provincias afectadas, con el propósito de negociar la anulación de las expulsiones y reconstruir el partido. Ante la imposibilidad de llevar adelante ese proyecto los ex dirigentes Lara, Ruiz Morcillo y Trillo intentarán la organización de un partido de Izquierda Andaluza, cercano al modelo de Euskadiko Ezquerra o Izquierda Gallega, pero la idea, puesta en marcha en otoño de 1981, se abandonará definitivamente en el mes de mayo siguiente, entre otras cosas por problemas de financiación. Por otra parte, el voto a Suárez no sólo había desencadenado una crisis irreparable, sino que trajo también como consecuencia el fracaso definitivo del incipiente Sindicato Andaluz, que había conseguido éxitos notables en las elecciones de Bazán y Astilleros de Cádiz (testimonio de Ruiz Morcillo).

Con motivo de su parca información sobre el Congreso extraordinario, Andalucía Libre anunciaba que estaba previsto uno ordinario para mayo, en el que posiblemente se plantearía "un profundo debate ideológico» y se discutiría "tanto la estrategia como el modelo de partido», cuestiones obviadas en la reunión de diciembre, como ya se dijo. El cuarto Congreso se celebraría, finalmente, en junio de 1981. De un lado, se hace balance de los primeros cinco años de legalidad del partido, concretando su estrategia y subrayando el «efecto multiplicador» causado por su presencia en la esfera po-

29 En el II Congreso Nacional (Palma de Mallorca, 6, 7 y 8 de febrero de 1981), Agustín Rodriguez Sahagún y Rafael Calvo Ortega, candidatos oficialistas a los cargos de presidente y secretario general de UCD, respectivamente, obtuvieron el 60,5 por 100 y 65,2 por 100 de los votos. En el Consejo Polftico, los críticos obtuvieron el 38,7 por 100 de los puestos, trente al 61,2 por 100 de los oficialistas.

3. En la reunión del Comité Ejecutivo del 27 de octubre, preparatoria del X Congreso, se produce un hecho insólito: por primera vez en muchos años se somete a votación el informe del secretario general, con el resultado de 24 votos a favor. dos en contra (Antoni Gutiérrez y Roberto Lertxundi) y cinco abstenciones (Camacho, Tamames, Manuel Azcárate, Pilar Bravo y Martín Lillo). Esto era sólo el preámbulo de la reunión del Comité Central de 1 de noviembre, altamente conflictiva, y de la nueva reunión del Comité Ejecutivo (22 de diciembre), auténtico pistoletazo de salida de la crisis del partido. Véase Pedro Vega y Peru Eraormin, Los herejes del PCE, Barcelona, Planeta, 1982, pp. 43-44 y 48; y Manuel Azcírate, Crisis del eurocomunismo, Barcelona, Argos Vergara, 1982, pp. 76 y 104-114 (Azcárate da los siguientes resultados sobre la votación mencionada: 23 a favor, tres en contra y seis abstenciones). 
lítica: «nuestra existencia como colectivo ha obligado a las demás fuerzas políticas a optar por Andalucía, favoreciendo en los últimos años una dinámica de la que todos somos testigos» (con ello se alude al cambio de actitud en los partidos de izquierda, "poniéndose apellidos andaluces" y apoyando una autonomía plena que, tras las graves repercusiones para UCD del referéndum del 28 de febrero, tendría que aceptar también el partido del Gobierno); se analizan igualmente las causas y actitudes ante la crisis del partido, poniendo el énfasis en la defensa frente a las acusaciones de ambigüedad y en la existencia de manipulaciones y campañas desatadas contra el PSA por otros partidos. De otro lado, a partir de un examen del contexto internacional y español (aquí se critica la «nueva estrategia de concentración" despertada por el $23-\mathrm{F}$, en particular las medidas de freno a los nacionalismos), se avanza la nueva estrategia del partido en una doble vertiente, interna y externa: en la primera, se propone la reestructuración y el fortalecimiento de la organización, mediante una mayor nitidez en los planteamientos teóricos de nacionalismo de clase, la mejora del funcionamiento interno y la consolidación del sistema de financiación. En la segunda, de actuación política propiamente dicha, cabe distinguir dos facetas: una estrategia de penetración en el sistema social andaluz (el partido ha de ser participativo y no de cuadros) y una estrategia de incidencia en el proceso autonómico con objeto de concienciar al pueblo andaluz, influyendo sobre los modernos medios de comunicación y potenciando los medios propios ${ }^{31}$. Lo que sin duda subyace en todo momento es, de un lado, el sentimiento, latente pero manifiesto, de que no se ha superado la crisis interna; y de otro, el temor a un fracaso electoral, dado el daño sufrido por la imagen del partido, no ya sólo porque continúe dando la impresión de estar dividido sino, sobre todo, por los efectos de su ambigua actitud en el Parlamento.

Los estatutos experimentaban algunas modificaciones significativas. Así, en la exposición de motivos, permanece la referencia a la necesidad de «huir de los peligros de la degeneración oligárquica», pero se añade ahora la de huir igualmente del «voluntarismo acientífico», para matizar que con lo anterior no debe incurrirse «en un rechazo, que sería utópico, de la autoridad de la dirección". Consecuentemente con esto, se introduce un nuevo órgano en la estructura del partido, la Comisión de Disciplina, y todo un apartado referente al tema. Por otra parte, ya no se habla de Secretaría General, desapareciendo, por tanto, aquello de que no podía ser unipersonal. Sin embargo, la figura del secretario general queda al frente del Comité Nacional, acompañado de un vicesecretario general y de los titulares de las Secretarías funcionales: Acción Política, Estudios, Financiación, Información y Organización; los titulares de las Secretarias sectoriales: secretarios nacionales de Emigración, Juventudes Andalucistas, Política Autonómica, Política Municipal, Política Parlamentaria y Política Sindical; y los titulares de las Secretarías territoria-

${ }^{31}$ Declaración del IV Congreso, 1881. 
les: primeros secretarios de las ocho provincias andaluzas y de las «circunscripcionales territoriales fuera de Andalucía donde exista pueblo andaluz»; además de otros miembros elegidos sin afección a una Secretaría concreta. El papel del secretario general queda aún más reforzado estatutariamente al disponerse la creación de una Comisión Delegada del Comité Nacional, elegida por este último, facultada con las competencias que le delegue el propio Comité e integrada por el secretario general y aquellos de sus miembros «que resulten elegidos a este fin» - no se dice cómo ni por quién-, excepción hecha de los titulares de las Secretarías territoriales. Además, el secretario general, junto al presidente del partido - figura también nuevay al presidente de la Comisión Permanente del Congreso, constituyen otro nuevo órgano: el Consejo de Presidencia, que tiene funciones de coordinación, pudiendo convocar y presidir en reunión conjunta al Comité Nacional y a la Permanente. Sin embargo, el hecho de que en este congreso se vincule la presidencia del partido con la candidatura oficial del mismo a la presidencia de la Junta de Andalucía, divulgada en octubre de 1981 con motivo de la campaña del referéndum de ratificación, y de que el primer presidente y candidato sea Uruñuela, y no Rojas Marcos, denota que en el propio partido se percibe al secretario general como algo «quemado», condición a la que por entonces no escapaba el resto de sus colegas al frente de partidos durante la transición, a excepción de Felipe González.

Las esperanzas de relanzamiento pasaron a centrarse en las elecciones autonómicas del mayo siguiente, a las que se acudirá con unos planteamientos posibilistas: "No existe la más mínima coyuntura revolucionaria de cambiar las cosas, aparte de que habría mucho que hablar sobre la bondad del método, y hemos de contentarnos con pequeñas modificaciones -eso sí, sustanciales- que permiten ir corrigiendo el signo degradante de nuestro subdesarrollo. Hemos de fijar lo que aquí, ahora y en estas circunstancias es posible hacer (...) sería importante que al menos se cumpliese realmente aquello ya legislado» (Programa electoral, febrero de 1982, págs. IX-X). Como es sabido, el descalabro fue mayúsculo, provocando la inmediata dimisión de Rojas Marcos como secretario general y su sustitución por Uruñuela, sucedido a su vez en la presidencia por Diego de los Santos, con Miguel Angel Arredonda como vicepresidente. El relevo no daría mejores resultados, como se comprobaría en las elecciones generales y luego en las municipales. En el supuesto de que el PSA hubiese superado la crisis interna que, como se ha visto, quedó abierta a poco de desembarcar en las instituciones, desde luego tal «resolución» no había llegado al elector, ante el que, entre otras cosas, seguía apareciendo como un partido débil, frente a la imagen de «fuerza» que ofrecía el PSOE o incluso AP.

En cualquier caso, el que a la altura de febrero de 1984, el partido se vea abocado a afrontar formalmente, en la Declaración de su $\mathrm{V}$ Congreso, una marcada reconversión ideológica, evidencia que, en ese terreno al menos, seguía sin cerrarse una crisis que, sin duda, ahora lo era fundamentalmente 
de identidad. Al frente del partido continuará el mismo equipo que se hiciera cargo del mismo tras las últimas derrotas en las urnas, pero tanto el marxismo como el socialismo son orillados en la ponencia ideológica de una formación política que pasará a denominarse Partido Andalucista. Una nueva etapa quedaba abierta, etapa que, como ya adelantábamos al principio, escapa al objetivo de este trabajo.

\section{LOS COMPONENTES IDEOLOGICOS}

La misma evolución de un partido que ha conocido cinco congresos y atravesado. de noviembre de 1973 a octubre de 1982, por una variedad de fases que van desde la clandestinidad a la condición de extraparlamentario en el ámbito estatal, pasando por la de partido testimonial y la de protagonismo parlamentario, incluso con grupo propio, dificultan la tarea de abordar un ensayo de caracterización de los rasgos definitorios de su ideología. Cabe sumar a este obstáculo la mencionada carencia de estudios sobre el tema y, sobre todo, el liecho de que la ambigüedad sea precisamente una de las notas más destacadas en los pronunciamientos y actitudes ideológicas del PSA, cuya identificación intentamos ahora.

\section{Bases ideológicas de partida}

El proceso de configuración ideológica del Partido Socialista de Andalucía difícilmente puede entenderse sin acudir a la etapa ASA, de la que arrancó el partido. Observaremos de este modo cómo la organización aparece doblemente vinculada en sus orígenes a un personalismo cristiano que conecta con el socialismo autogestionario y a la tradición andalucista. Lo primero resulta evidente tras un somero examen del «Manifiesto fundacional» de ASA, en el que personalismo y socialismo son destacados, junto a la democracia, como los principios básicos sobre los que construir un «mínimo patrimonio común" ${ }^{32}$. A diferencia del socialismo, donde se hace mención expresa de la autogestión, el personalismo no se define explícitamente como cristiano, pero se desprende de la presentación que de él se hace y del mismo léxico empleado: la búsqueda en el socialismo de "sus actitudes solidarias y éticas que hacen posible la plena realización del hombre», «la violencia del oprimido», el propio planteamiento inicial de la lucha contra la dictadura como una «obligación moral» de los ciudadanos, la voluntad de «dejar testimonio», la «búsqueda permanente», el «no apego a las estructuras», «el compromiso políticon, etc. ${ }^{33}$. Probablemente no es casual que la idea y el término mismo de «compromiso" que, como se recordará, fue adoptado

32 Manifiesto fundacional, loc, cit., pp. 97-99.

${ }^{33}$ Ibidem, passim. 
también para autodenominarse por los CP, SA, que dieron lugar a ASA, constituya parte esencial del pensamiento de Emmanuel Mounier, sin duda uno de los más cualificados e influyentes representantes del personalismo cristiano, como se sabe el predominante en Francia. A los efectos de nuestro análisis, nos interesa destacar un par de notas de las que según este filósofo caracterizan las «estructuras del universo personal»: a) «Enfrentamiento o exposición, por los cuales la persona puede protestar, elegir y conseguir la libertad», y b) "Compromiso (engagement) que posibilita y hace fecunda la acción» ${ }^{34}$. Este pensamiento causaría un gran impacto entre los núcleos cristianos de izquierda que se oponían al régimen franquista y de donde procedían una buena parte de la originaria militancia del PSA y algunos de sus más destacados dirigentes, entre los cuales, sus dos secretarios generales, Alejandro Rojas Marcos, muy próximo a la HOAC sevillana, y Luis Uruñuela, fundador y presidente de las Juventudes de Estudiantes Católicos ${ }^{35}$; y el primer teniente de alcalde del Ayuntamiento de Granada, Arturo González Arcas, líder de la FECUN granadina en los años sesenta ${ }^{36}$. La conexión entre cristianismo de izquierdas de índole «partisana» y socialismo autogestionario en la ideología que caracterizó a ASA estaría inspirada por los modelos franceses de la CFDT y el PSU, según una interpretación reciente ${ }^{37}$. Sin embargo, el Parti Socialiste Unifié reunía un elenco bastante más variado de

34 Véase J. Ferrater MORA, Diccionario de Filosofía, 3.' ed., Madrid, Alianza Editorial, vol. 3, 1981, pp. 2280-2281 y 2555-2556.

${ }^{35} \mathrm{El}$ primero, alumno en los Jesuitas y "educado en los principios de una ética cristiana", según reza la biografía que de él hace Andalucía Libre (núm. 11), estuvo ligado a Joaquín Ruiz-Giménez, como él, abogado, empresario y político. Por su parte, Uruñuela formó parte de los "movimientos católicos especializados", en la Sevilla de los años cincuenta, y fue miembro de los Grupos de Compromiso Político por Andalucía, junto a Rojas Marcos. Dada su amistad con este último y el protagonismo en la mencionada organización estudiantil, debió estar también vinculado a don Joaquín, en tiempos secretario general de la Confederación de Estudiantes Católicos y, como él, accionista de El Correo de Andalucía.

${ }^{36}$ La Federación de Estudiantes Católicos Universitarios estaba auspiciada por la Compañía de Jesús (sus siglas primitivas eran FECUM, respondiendo la " $M$ " al término "Marianos"). El núcleo fundacional del PSA en Granada estuvo inte. grado sustancialmente por personas procedentes de esta organización y, curiosamente, se engrosaría con un buen número de elementos que venían de los grupos scouts (introducidos en la ciudad a principios de la década de los sesenta por religiosos enseñantes, tuvieron su foco de irradiación en las escuelas del Padre Manjón), canalizados hacia el partido por Eladio Fernández-Nieto, miembro de la comisión permanente de ASA.

37 Javier Rodrfguez del Baraio y Eduardo Sevilla Guzmán, "El corporatismo como enfoque para el análisis de la cuestión nacional en la actualidad: aproximación al caso andaluz", Córdoba, noviembre 1982 (ejemplar multicopiado), p. 21 (trabajo publicado, con ligeras modificaciones, como "Nacionalismo y corporativismo: Aproximación al caso andaluz", en Revista Internacional de Sociología, número 45, enero-marzo 1983). La Confederación Francesa Democrática de Trabajadores, con la que resurge el modelo autogestionario en el Mayo francés, es presentada desde el partido como "el primer sindicato occidental que ha hecho suya esta antigua tradición de la clase trabajadora". USO sería el sindicato español más cercano a sus planteamientos -equipo de formación del PSA-, El socialismo autogestionario, Sevilla, Dolmen, 1977, p. 13. 
corrientes ideológicas y de militantes: en él concurrían, junto a los cristianos de izquierda, intelectuales doctrinarios ex comunistas, elementos obreros marxistas y socialdemócratas anti-Mollet, por lo que el PSU, aunque «unificado», nunca fue un partido unido, ni siquiera en la primera fase ${ }^{38}$.

En cuanto al enlace con la tradición andalucista, cabe decir que en el citado manifiesto no hay referencia alguna a las iniciativas y movimientos históricos de este signo, aunque sí, por ejemplo, en el Anteproyecto de Estatuto de Autonomía presentado por ASA en Sevilla el 7 de mayo de 1976, como «documento de trabajo para las organizaciones de la oposición de. mocrática existentes en esa región, y, en general, para todos los andaluces»: en la introducción al articulado se hace mención expresa de la Asamblea de Córdoba de enero de 1933, que aprobó las Bases para el Estatuto de Andalucía, como eel antecedente de no pocas de las disposiciones que contiene el nuevo Anteproyecto», y se reconoce «el importante papel que en aquella ocasión desempeñó la Junta Liberalista de Andalucía», para finalizar recordando a su principal dirigente, Blas Infante, como «líder del autonomismo andaluz» ${ }^{39}$. En el II Congreso del PSA la referencia expresa al «entronque con el andalucismo histórico» es incorporada definitivamente a la exposición de motivos que abre sus estatutos.

\section{Modelo de organización política}

El PSA defiende en teoría un socialismo democrático que llegue a través de procedimientos electorales y parlamentarios. Aquí, como en muchos de los temas fundamentales, no hay diferencias reales con el PSOE y el PSP (lo que es admitido implícitamente en alguna ocasión desde las páginas de Andalucía Libre). Basta repasar las «Bases mínimas de coincidencia ideológica» aprobadas en el I Congreso del PSA y reafirmadas en la declaración del siguiente: 1) marxismo crítico «como teoría política para la interpretación de la historia y como método correcto para el análisis de la realidad y de su transformación»; 2) lucha de clases como motor de la sociedad y como "proceso dinámico» hacia la sociedad socialista; 3) el objetivo de una sociedad socialista, percibida como democrática y autogestionaria; 4) sindicalismo de clase, unitario, democrático, autónomo e independiente, y 5) unidad «de las fuerzas democráticas, hoy, y de la izquierda mañana», como vía hacia el objetivo inmediato: la transformación del Estado franquista.

Estos planteamientos ideológicos coinciden sustancialmente con aquellos que se hacían desde los partidos citados o desde los que integraban la FPS, aunque, al igual que ocurre con estos últimos, se pone mayor énfasis en la

38 Cf. D. Pickles, The Fifth French Republic. Institutions and Politics, 3.* ed. Nueva York, Praeger, 1966, pp. 82 y ss.

39 Ejemplar multicopiado, p. 1. 
autonomía regional-nacional ${ }^{40}$. Igualmente, el partido se define como «de clase» en los estatutos aprobados por el I Congreso, si bien esta autocalificación, que se hace compatible con el pluralismo como en el caso del PSOE, desaparece en posteriores redacciones. En un intento de marcar las diferencias con su principal rival electoral, en su etapa extraparlamentaria, el PSA subrayará, a través de las manifestaciones de sus líderes, su carácter de "partido socialista y no socialdemócrata ${ }^{41}$. Pero, como veremos enseguida con más detalle, a partir del II Congreso primará en todo momento «lo andaluz» sobre lo socialista, que irá diluyéndose hasta desaparecer.

En cuanto a la forma de gobierno y del Estado, el PSA se pronuncia claramente por la república en su primer Congreso (ya lo hacía en el manifiesto de ASA), mientras que en el segundo tema se muestra menos tajante que otros partidos de la familia socialista en aquellas fechas, al menos a niveles programáticos: el Estado español se debería articular «de forma que reconozca un amplio margen de autonomía para las distintas comunidades regionales y nacionales, que permitiría adoptar fórmulas de organización que irían desde el Estado regional al Estado tederal». Sin embargo, tal conformación de la estructura estatal se hace depender del respeto de un par de principios: a) que el Estado conserve los medios para garantizar la compensación de las regiones más desfavorecidas, y b) que todas las regiones y nacionalidades tengan los mismos derechos respecto de su autonomía, «quedando a la libre disposición de cada pueblo la determinación del grado que desea dentro de los límites establecidos».

En consonancia con la actitud del resto de los partidos de izquierda, se rechaza el modelo reformista adoptado desde el Gobierno para el tránsito del franquismo a la democracia capitalista, exigiendo el "desmantelamiento de las estructuras e instituciones nacidas de la dictadura». Pero tampoco aquí hay originalidad alguna; se termina renunciando a la ruptura y aceptando la monarquía.

Los aspectos más novedosos en la ideología del PSA residían, sin duda, en su afirmación andalucista articulada teóricamente con el socialismo mediante la agregación del factor regionalista o nacionalista, cuestión que pasamos a examinar.

\section{El andalucismo}

En su fase como ASA, hay ya un sentimiento andalucista que, no sin acierto, ha podido ser caracterizado como «eminentemente emotivo" ${ }^{42}$, generado por una percepción de Andalucía como región discriminada por el

* Cf. Elías, Díaz, Socialismo en España: el partido y el Estado, Madrid, Ed. Mezquita, 1982, pp. 82-84.

4 Véase, por ejemplo, la reseña del mitin de Rojas Marcos en Zafarraya (Granada) ante 1.500 personas, en Ideal, 21 de mayo de 1978.

42 Véase J. Rodrfaez det Barrio y E. Sevilla, loc. cit., p. 21. 
centralismo, en situación de "subdesarrollo colonial», en la que sus gentes sufren los más altos índices de analfabetismo, paro y explotación ${ }^{43}$, y los más bajos en industrialización, vivienda, etc. Esto se traduce a un nivel programático en la reivindicación de un «regionalismo solidario», en el marco del cual se obtenga un estatuto especial que reconozca la personalidad política de Andalucía. Dicho reconocimiento traería aparejada «la existencia a nivel regional de una asamblea representativa de sus hombres y de un ejecutivo gestor de sus intereses», es decir, lo que se denomina un poder regional. $\mathrm{Y}$ se añade explícitamente que ese regionalismo solidario «no se opone a que otras regiones que deseen una mayor autonomía puedan negociarla expresamente». $\mathrm{Si}$ en el Congreso constituyente se asume sustancialmente tal posición, definiéndose el partido como «regionalista socialista», en el siguiente (enero de 1979), se critica esta calificación para proclamarse nacionalista, adoptando la doble denominación PSA-Partido Andaluz.

El cambio de actitud ideológica y programática en el PSA, a las puertas de la doble convocatoria electoral a Cortes ordinarias y a los entes locales, podría explicarse por la incorporación al partido de las Juntas liberalistas, pero tiene también ciertos visos de oportunismo político. En efecto, habida cuenta de que acaba de aprobarse lo Constitución, cuyo artículo 2 establece la distinción entre nacionalidades y regiones, y previéndose un trato más favorable para las llamadas nacionalidades históricas, jugar la baza del agravio comparativo, afirmando la propia identidad racional se iba a revelar sumamente rentable a efectos electorales. Además, en la medida que el PSOE, el PCE o la UCD asumían, al menos formalmente, los planteamientos regionalistas para Andalucía, incluida la reivindicación del estatuto de autonomía, se trataba de huir hacia adelante para ganar espacio político ${ }^{44}$. Por último, y no es lo menos relevante, estaba la experiencia histórica del nacionalismo catalán y vasco, y la más próxima de las elecciones a Cortes constituyentes, donc'e partidos de este signo habían obtenido 12 y 9 escaños, respectivamente, cuando los regionalistas sólo alcanzaron un escaño, el del Partido Socialista de Aragón.

El hecho de que el discurso ideológico esté motivado por los términos

"3 Repárese en los términos en que se presenta, por ejemplo, la biografía del parlamentario Rojas Marcos: "Ingresó en la Universidad de Sevilla, cursando la carrera de Derecho. Al propio tiempo, y por decisión de su padre, trabajaba administrando una de sus granjas, secundado por un campesino... analfabeto, pero con una inteligencia nata: 'Allí - dirá más tarde- entré en contacto con el mundo real, comprobé la condición social de los trabajadores, gente que entonces trabajaba veinte horas diarias para pagar una vaca que había comprado a crédito'." Quién es quién en las Cortes Generales, 1979-1983, Documentación Española Contemporánea, p. 617.

" En la declaración del II Congreso se trata de justificar este salto ideológico denunciando el "oportunismo regionalista de los partidos centralistas de izquierda y de derecha" que han "desnaturalizado e instrumentalizado" el concepto de regionalismo (pp. 7-8). 
en que evoluciona la confrontación política, incide sobre la autodefinición nacionalista que presenta inevitablemente una elevada dosis de ambigüedad ${ }^{45}$. Esto hace que, aunque el PSA se proclame como "partido andalucista y de izquierda», viendo en ella uno "doctrina innovadora» a la vez que «un hecho sin precedentes» ${ }^{46}$, no siempre sea percibido así desde fuera, incluido un sector amplio de su electorado ${ }^{47}$. Lo último era reconocido implícitamente por su propio secretario general: «nos sentimos orgullosos de haber recibido el voto de muchos andaluces que no coinciden totalmente con nuestro ideal, y que nos han votado porque consideraron que el PSA representa los intereses del pueblo andaluz» ${ }^{48}$. Incluso desde el mismo seno del partido hay quienes asumen explícitamente ésto como crítica, a raíz del fracaso en las autonómicas: «el andalucismo no sólo tiene que ser de izquierdas, sino que debe parecerlo y pregonarlo" ${ }^{49}$. Es el tema de la ambigüedad, no ya a nivel teórico, sino en su práctica política, especialmente en la etapa parlamentaria. Difícilmente podía verse como de izquierdas a un partido que lo primero que hace al llegar al Congreso es apoyar la investidura de Suárez, para volverle a respaldar en un punto crítico del proceso autonómico, otorgándole su confianza, oponiéndose luego al desbloqueo de éste por la vía del 151 en las negociaciones UCD.PSOE.

Volviendo al plano del discurso ideológico, la ecuación andalucismo $=$ = nacionalismo + socialismo no deja de resultar algo equívoca. $Y$ lo es, sin duda, la afirmación de "que un nacionalista tiene que ser de izquierdas y que un socialista andaluz tiene que ser nacionalista, sin que una cosa monte más sobre la otra», como toda respuesta a la lógica pregunta sobre si prima más el andalucismo o el socialismo ${ }^{50}$. A mi juicio, resultaba algo incoherente que, percibiendo el partido como socialista, los llamados andalucistas históricos pudieran justificar su integración en el mismo, argumentando simple y llanamente que «los análisis de este colectivo coincidían con los nuestros» ${ }^{51}$. Esto sólo tenía en principio dos explicaciones. Una, que los históricos son socialistas, cosa bastante dudosa ${ }^{52}$. Otra, que en última instancia no venían

43 Cf. J. Rodriguez del Barkio y E. Sevilla, loc. cit., pp. 8 y 18.

" Enrique Inresta, "¿Cómo ves el futuro, compañero?", Andalucía Libre, número 50 (octubre 1982).

${ }^{4}$ Véanse las variables que llevan a una calificación ideológica de centro-izquierda del electorado del PSA-PA, según el Informe FOESSA (1975-1981), pp. 571 y ss. Pese a que la encuesta está hecha sobre una muestra muy pequeña, los resultados pueden considerarse bastante ilustrativos.

${ }^{4}$ Declaraciones de Rojas Marcos a Andalán, de Zaragoza (marzo 1979), p. 3.

49 Martí Risquer, "Resultados electorales. Análisis comparativo", Andalucía Libre, núm. 48 (junio 1982), p. 9.

so Declaraciones de Rojas Marcos a Andalán, cit.

st "Manifiesto de los andalucistas históricos", Andalucía Libre, núm. 47 (mayo 1982), p. 17.

52 Este movimiento andalucista arranca del regeneracionismo (las ideas de Costa ejercieron notable influencia sobre Blas Infante). La Junta Liberalista, de la que apenas quedaban ya una docena de miembros, nace como un movimiento intelectual apoyado $\mathrm{y}$ vehiculado por grupos pequeño burgueses $\mathrm{y}$ de clases me- 
como tal al PSA. Lo de la identificación socialista era algo tan dudoso que, ni siquiera las más tempranas propuestas para que el partido hiciera desaparecer la $\mathrm{S}$ de sus siglas, levantaron mayores protestas ${ }^{53}$. Tal posibilidad se plantearía seriamerite en algunos sectores del partido durante la primavera de 1983 y de cara al V Congreso, proponiéndose inicialmente la sustitución de la $\mathrm{S}$ por la $\mathrm{N}$ de «nacionalista». Por supuesto - se dirá-, sin que ello suponga abandonar la conciencia izquierdista, sino como forma de evitar la confusión entre PSA y PSOE que existe en zonas «poco informadas» de la comunidad autónoma ${ }^{54}$. Sabido es en qué quedó todo ésto.

El mismo tema del poder andaluz, proclamado por primera vez en 1975, puede tener cierta origiralidad en cuanto expresión (no se habla de un poder vasco, aragonés o gallego), pero resulta también equívoco. Así, unas veces se presenta como poder popular andaluz (especialmente en los escritos de José Aumente, el ideólogo de mayor altura dentro del partido), pero normalmente se prescinde de ese adjetivo y no queda claro que ese poder tenga que ser necesariamiente socialista, ni siquiera de izquierdas. Veamos un par de ejemplos de declaraciones de dirigentes del partido, correspondientes a 1977: "Lo que nosotros llamamos poder andaluz» consiste en «la aceptación primero y la creación después por parte del pueblo y de los organismos que lo representan (partidos políticos, organizaciones sindicales, etc.) de unos órganos de gobierno y deliberación autónomos, es decir, independientes del poder central del Estado» ${ }^{55}$. La forma en que se construye «un poder andaluz fuerte, representativo y democrático, en el que entren todas las fuerzas políticas y sociales de Andalucía», no es otra que un proceso político por el que se crea "un parlamento y un Gobierno específicos de Andalucía» ${ }^{56}$. O la Declaración del IV Congreso, donde se afirma: «Lo importante, en definitiva, es que se cuente con un poder andaluz... El objetivo fundamental de nuestro partido es conseguir el necesario poder andaluz como para elaborar y decidir nuestra propia estrategia de desarrollo. Es decir, que seamos nosotros solos, desde aquí, independientemente de otros intereses extraños, quie

dias, que tendría como focos de irradiación los Centros Andaluces; pero los componentes socialistas están ausentes de su ideario, salvo que se tomen como tales los principios cooperativistas. Cr. J. AcosTa, Historia y cultura del pueblo andaluz, Barcelona, Anagrama, 1979, p. 78; y J. A. LAcombA, "Andalucía: trayectoria de un regeneracionismo", estudio preliminar a Blas Infante, El ideal andaluz, Madrid, Túcar, 1976, pp. 30 y ss, (Acosta ha hablado de anarco-andalucismo para referirse al ideario de la Junta).

5 Véase Andalán, cit.

54 En algunos círculos el cambio de siglas se puso en relación con una estrategia de acercamiento a la solución Roca, en la que el PSA se integraría junto con PNV y CiU (El Pais, 8 de mayo de 1983, p. 21). No obstante, esto último ha sido descartado después por el secretario general, que sí afirmó que el partido se abrirá a tendencias políticas no socialistas (El País, 17 de mayo de 1983).

${ }_{35}$ José L. Espejo, miembro del comité ejecutivo del partido, en Andalucía Libre, núm. 7 (15 mayo 1977).

56 Pedro Ruiz Morcillo y Eladio Fernández-Nieto, del comité ejecutivo y del comité provincial de Granada, respectivamente (Ideal, 10 de agosto de 1977). 
nes decidamos 'lo que hay que hacer' para salir de nuestra postración y subdesarrollo.»

Si en el último caso se añade que quienes ejerzan dicho poder andaluz tendrían que ser inevitablemente las «fuerzas progresistas y populares», y en los anteriores se habla al mismo tiempo de la lucha contra las «estructuras de dominación» del "socialismo específico del pueblo andaluz», el concepto continúa siendo equívoco: Gobierno socialista y Parlamento autónomo con esa maycría los hay ya en Andalucía, pero a buen seguro que para el PSA esto no supondría que existiese un poder andaluz, porque no son vistos como auténticamente «independientes del poder central del Estado». Pero ¿lo habría si ostentase aquella mayoría un partido nacionalista de derechas o en el continuum centro derecha, como ocurre en Cataluña o en el País Vasco? No, se diría, porque el andalucismo es nacionalismo socialista... Y, sin embargo, parece añorarse el amplio apoyo a esos partidos, que no se duda en calificar de «popular»: «nuestras posibilidades reales de poner en marcha los mecanismos que deben resolverlas (las necesidades de Andalucía)... sólo se harán realidad cuando seamos el partido mayoritario de los andaluces, fruto de un fuerte respaldo popular, como ocurre con los vascos y catalanes» 57 .

En última instancia, el andalucismo del PSA, el que arrancó votos en 1979, tiene bastante, si no de anti, sí de «no ser menos que», pensando fundamertalmente en el País Vasco y Cataluña. De ahí, el éxito electoral del argumento del agravio comparativo, tema recurrente desde antes del primer Congreso, que ciertamente responde a una realidad social y económica, como igualmente existió alguna suerte de discriminación en el plano políticoconstitucional.

Así, en un falleto del partido, correspondiente a la etapa previa a aquellas elecciones, puede leerse: «la estrategia de los andaluces, cara a su autodeterminación, tiene que estar condicicnada por lo que en otros pueblos se haga... los vascos y catalanes no pueden construir su autonomía sin mirar a los demás, sin respetar la autodeterminación de los demás»; y finaliza reivindicando un «trato en pie de igualdad con los otros pueblos españoles», así como la necesidad de cobrar conciencia de la propia identidad porque, si no, «seguiremos siendo españoles de tercera categoría». Hay, pues, un sentimiento de estar en condiciones de inferioridad unido a un fuerte recelo hacia cualquier abuso basado en esa situación, hasta tal punto que el tema llega a veces a hacerse cbsesivo: "País, sí; región, no», gritaban los manifestantes que habían acudido a la primera convocatoria del «Día Nacional del País Andaluz», en diciembre de 1977. Todavía en la declaración del IV Congreso, desbloqueado el Estatuto de modo que Andalucía alcanzara los niveles fijados en el artículo 151 , se subraya $€$ l sentimiento de indignación entendido como «agravio comparativo» que la emigración ha creado en Andalucía, para afir-

"7) Declaración del IV Congreso, p. 21. 
mar que «la transición democrática ha agravado ese sentimiento debido a la discriminación legal y real que sigue sufriendo Andalucía. «No somos españoles de segunda», proclama Andalucía Libre, en titulares de primera página (febrero de 1978), criticarido las declaraciones de Múgica sobre la conveniencia de dar a Cátaluña y País Vasco sistemás de autogobierno y a Andalucía tan sólo una descentralización.

\section{Otros rasgos}

En mi opinión, hay tres rasyos que, con demasiada frecuencia, han impregnado la práctica ideológica y política del PSA en su corta historia como partido: ambigüedad, misticismo y populismo. La ambigïedad, sobre la que ya henios dejado dicho algo, se manifiest: incluso en la doble imagen con la que se presenta ante el electorado desde 1979 a 1983: Partido Socialista de Andalucía, Partido Aridaluz. Llequrá un momento en que aquélla sea reconacida desde la propia dirección del partido. Al principio, sólo de manera implícita y tratarido todavía de justificarlo como la consecuencia normal de «esa gran contradicción dialécrica que se produce entre la eficacia práctica y la pureza ideológica (socialismo autogestionario)». Estaríamos ante el dilema de cualquier partido de izquierda: «O ensuciarse y transigir en el duro campo de la praxis política; o mantenerse testimonialmente puros, pero absolutamente inoperarites, $y$, por tanto, inútiles» ${ }^{58}$. Será después del fracaso en las átonómicas cuando el tema se plantee explícitamente, a modo de autocrítica, hablándose de las «ambigüedades cbjetivas» con que el PSA se había presentado a la carripaña, con un "mensaje político dirigido a todos los electores, es decir, a ninguno", apareciendo así «ante mucha gente del pueblo, como por encima del antagonismo derecha-izquierda»" ${ }^{59}$.

El misticismo, no exento de ciertos elementos mesiánicos, es proclamado y asumido como virrud, por quien fuera líder y cabeza visible del partido durante gran parte de su trayectoria: «En nuestro colectivo hay una auténtica mística. Todos, absolutamente todos los militantes estamos convencidos del papel histórico del PSA y esa seguridad es nuestra razón de ser, es lo que nos ha hecho superar todas las dificultades» ${ }^{60}$. Por ello, no deja de resultar contradictorio que luego se critique el «idealismo revolucionario e ingenuo» de los «disidentes», argumentando la necesidad primaria de «liberar a los movimientos revolucionarios - y más si son de nuevo cuño- de todo idea-

58 José Aumente, "Acerca de la crisis en el PSA", Andalucia Libre, núm. 33 (febrero 1981), p. 11. Aumente presidía entonces la Comisión Permanente del Congreso del PSA.

${ }_{59}$ Isidoro Moreno, "El futuro del andalucismo", Andalucía Libre, núm. 49 (julio-agosto 1982), pp. 11-12. El antropólogo y profesor de Sevilla escribe en páginas de opinión, siendo miembro del Comité Nacional del PSA, aunque procedente del disuelto PAU-PTA, lo que quizá explique su fuerte tono crítico.

bo Declaraciones de Rojas Marcos, cit. 
lismo, cualquier misticismo $y$ demás errores» ${ }^{61}$. En cuanto al tono mesiánico del mensaje, al margen de la misma imagen que pudiera transmitir el ex secretario general, es algo que estaba ya en Blas Infante, cuyo pensamiento es asumido bastante acríticamente: "Andalucía necesita una dirección espiritual, una orientación política... y una fuerza que apostole y salve» ${ }^{62}$. Me parece observar aquí un cierto paralelismo con el carácter evangelizador con el que los anarquistas concibieron su misión difusora de un ideario que tanto arraigo tuvo en Andalucía. Curiosamente, el párrafo que cierra la declaración del IV Congreso contiene un par de frases - "No vale la pena vivir si renunciamos al cambio. No vale la pena querer cambiar si no vamos a vivir para poder hacerlon- que traen a mi memoria las palabras de Bakunin: «Sé que moriré y que los gusanos me comerán, pero quiero que triunfe nuestra idea.»

El populismo es algo que cualifica al mensaje nacionalista del PSA, que algunos autores no dudan en calificar como «populista de derechas», para las fases $1978-80$ y $1980-82$, áludiendo a la defensa de un proyecto político «de marcado carácter interclasista, en el que la defensa en abstracto de Andalucía ocupa un lugar destacado, por encima de los conflictos internos que se desarrollan en ella» ${ }^{63}$. Aunque el carácter interclasista es negado en todo momento desde las publicaciones del partido, lo de populista termina admitiéndose por algunos de sus dirigentes. Como ocurriera con el tema de la am. bigüedad, primero se hará indirectamente y sin ver en ello algo condenable: «Todo nacionalismo en zona subdesarrollada es objetivamente revolucionario; no podrá ser nunca burgués o interclasista (mcdelo Clavero), sino, todo lo más, convertirse en 'populista' ${ }^{64}$. Luego, directa y críticamente, calificándolo incluso de oportunista; el error de haber sustituido el enfrentamiento izquierda-derecha por el de andalucismo-centralismo no habría sido sólo táctico, pues «no dejaba suficientemente claro ante el electorado que éste debía votar izquierda, sí, pero izquierda nacionalista» (y que éste era el carácter del PSA), simo que «reflejaba una clara dosis de populismo oportunista» ${ }^{65}$.

\section{LAS SEÑAS DE IDENTIDAD}

\section{Aspectos generales}

Atendiendo básicamente al plano estructural sin dejar de considerar algunos elementos ideológicos, cabe apuntar las siguientes características para

${ }^{61}$ José Aumente, loc. cit. El subrayado es nuestro.

${ }^{62}$ Palabras de presentación a los atenistas sevillanos de El Ideal Andaluz, cit., p. 39. Infante desarrollará esta idea en el capítulo IV de su obra (pp. 108 y ss.).

63 J. Rodrfiuez del Barrio y E. Sevilla, cit., pp. 19-20. A su vez, los profesores de Córdoba identifican como "populista de izquierdas" al nacionalismo de ASA (regionalismo, diría yo) del "sector crítico" del PSA en la fase 1978-1982 y de sectores procedentes del PAU-PTA, luego integrados en el PSA.

* J. Aumente, loc. cit. (subrayado, nuestro).

Isidoro Moreno, loc. cit., p. 12. 
el PSA: a) partido de naturaleza regional, circunstancia que contribuyera a dibujar uno de los rasgos típicos de nuestro actual sistema de partidos, la presencia de un subsistema regional; b) debilidad interna y falta de consolidación, notas ambas que definen tanto al sistema de partidos como a una buena parte de las fuerzas políticas que lo integran ${ }^{66}$. Ya tuvimos ocasión de ver cómo el PSA ha pasado por congresos, crisis y abandonos masivos que traslucen problemas de definición ideológica y de consolidación orgánica, la dificultad de hallar la propia imagen de cara al electorado, etc.; c) fuerte peso específico de la época testimonial (período de la clandestinidad y extraparlamentario): el partido comienza a crecer a partir de agrupaciones informales de amigos que aglutinan compañeros, colegas y familiares, entre los que predominan más los elementos propios del psicogrupo que del sociogrupo ${ }^{67}$, y esto se refleja tanto en sus órganos de dirección como en algunas de las candidaturas electorales ${ }^{68}$; d) en conexión con lo anterior, proceso de concentración oligárquica prematuro y rápido, traducido en una neta hegemonía del grupo sevillano, circunstancia que - ya se vio- contribuyó decisivamente al desencadenamiento de la crisis interna (algo tardíamente, en la declaración del IV Congreso, se subrayará la necesidad de que el partido sea "participativo», de manera que la «dialéctica base-dirección funcione en los dos sentidos»); e) partido fundamentalmente de militantes, y en alguna medida de cuadros, entre los que predominan enseñantes, jóvenes profesionales, comerciantes, empleados y estudiantes, en consonancia con los sectores sociales pequeño burgueses, y en general de clase media, entre los que ha tenido cierto arraigo ${ }^{69}$; f) partido interclasista, al menos a los efectos electorales, desde 1979, aunque este extremo se haya negado en las definiciones

of Cf. Antonio BAR, "El sistema de partidos en España. Ensayo de caracterización". Sistema, 47 (marzo 1982), pp. 5 y ss.

67 En este sentido, véase "La crisis del andalucismo político", en Andalucía Libre, núm. 31 (febrero 1981), p. 9.

${ }^{* 3}$ Ejemplo ilustrativo de lo primero sería el hecho de que, de los nueve miembros del primer comité ejecutivo, tres (Uruñuela, Emilio Pérez Ruiz y Juan Carlos Aguilar, todos ellos parlamentarios en 1979) eran o habían sido profesores de la Facultad de Derecho de Sevilla, de la que también fue alumno Rojas Marcos; o el que en el comité del partido en Granada predominaran los licenciados en Filosofía y Letras procedentes de la FECUM. Y una muestra de lo segundo, el que en las listas municipales al Ayuntamiento granadino en 1979 figuraban nada menos que tres "Eladios" (nombre por el que se conoce en la ciudad a los hermanos Fernández-Nieto) y cuatro pares de hermanos, sin contabilizar otros apellidos comunes; aunque en menor escala, las candidaturas a los ayuntamientos de Almería, Granada y Jaén en las recientes elecciones presentan todavía huellas de la incidencia del factor familia. (Obviamente, algo de esto ha ocurrido en no pocos partidos, sin excluir los históricos, durante la transición.)

${ }^{69}$ Esta apreciación y la que sigue, contrastadas ambas con elementos procedentes del partido, coincide sustancialmente con la impresión que apunta el mencionado Informe FOESSA, en el sentido de que el electorado del PSA-PA en 1979 destaca por su juventud y "es más de clase media que el de los partidos obreros, generalmente con algo más de educación, con unas dosis de clase media educada, con un limitado atractivo en el campo, especialmente entre braceros, pero también entre la clase obrera" (pp. 571-572). 
ideológicas hechas desde el partido; g) carácter eminentemente urbano. El partido carece de una sólida base agraria. A diferencia del PSOE, su fuerza en las capitales y ciudades mayores de 200.000 habitantes es mayor que la que tiene en los pueblos, algo que va en principio contra la consideración tradicional de la influencia rural de este tipo de partidos, más aún cuando la lamentable situación del campesinado andaluz ha sido siempre un argumento empleado por el partido para subrayar el abandono de la región. Esta escasa implantación del PSA entre el proletariado agrícola, que curiosamente intentó con algún éxito inicial a través de los teleclubs, le ha restado protagonismo político en las movilizaciones compesinas, lo que se ha achacado a dos factores concretos: de un lado, un cierto complejo ante los partidos tradicionales de izquierda; de otro, el «excesivo teoricismo y reducida actividad práctica de no pocos significados dirigentes, hipnotizados, además, por el espejismo de una presencia en las instancias institucionales -Parlamento de Madrid, ayuntamientos - que no esperaban en vísperas de las elecciones de $1979{ }^{70}$; h) finalmente, en el plano ideológico, y hasta el V Congreso, pueden señalarse ahora un par de cuestiones: la existencia de un cierto solapamiento con el PSOE, sobre todo desde que la federación sureña de éste se convirtiera al andalucismo, y la ausencia de un debate interno con trascendencia pública del tipo de los que han vivido el PCE o el PSOE, con el leninismo y eurocomunismo o el marxismo, respectivamente.

\section{Notas diferenciales como partido regional}

En este apartado, siguiendo en buena parte el esquema propuesto por Urwin $^{71}$, y aun a riesgo de reiterar algún punto, se trata de poner en relación el PSA-Partido Andaluz con otros partidos regionales de corte regionalista/nacionalista que han tenido o tienen representación parlamentaria a nivel estatal, al objeto de destacar los rasgos definidores del primero: a) juventud: estamos ante un partido político nuevo, a diferencia de otros partidos regionales, como el PNV, el PSC, el PSUC o ERC; b) quizá el único partido regional auténtico que llegó a cuajar en Andalucía ${ }^{72}$ y desde luego el único en estar presente en el Congreso de los Diputados, incluso con grupo parlamentario propio. Recuérdese la fallida experiencia de Unidad Andaluza, creado a partir del Partido Social Liberal Andaluz y presentado por Manuel Clavero el 27 de diciembre de 1980 como un partido «autonomista, interclasista y no marxista», que desaparecía del panorama político andaluz en la etapa pre-electoral de las autonómicas, con lo cual fracasaba el intento de plasmar en Andalucía un tipo de partido de centro-derecha en la línea de PNV o CDC; c) inexistencia de alianzas con algún otro partido

70 Isidoro Moneno, loc. cit., p. 12.

7 Derek W. UnwiN, loc. cit., passim.

72 Véase A. Checa, Las elecciones de 1977..., cit., pp. 13-16. 
a nivel estatal, en lo que coincide con la mayoría de las formaciones politicas nacionalistas: sólo lo haría a efectos puramente electorales con el PSP en los primeros comicios (al parecer, hubo un intento por parte de Rojas Marcos de hacer la unidad de la FPS con el PSP, de forma que éste se mantendría en el centro de España y se confederaría con los partidos de las nacionalidades y regiones, pero la operación no habría prosperado debido a las resistencias de Tierno) ${ }^{73}$. Es más, resulta poco probable que $\in$ n su nueva etapa como Partido Andaluz se llegué a una alianza de este tipo, como ciertamente inverosímil resultaba que se produjese una integración en el PSOE o en el PCE, por razones obvias, entre las que las diferencias y aún las hostilidades personales respecto al primero no eran lo menos importante ${ }^{74}$; d) desdibuje ideológico: presentándose como socialista y de izquierdas, no siempre fue percibido como tal ${ }^{75}$; e) relativamente radical en el terreno social, si se compara con la mayoría de los partidos políticos regionales; f) fuertemente sesgado hacia grupos de clase media, desequilibrio que aparece aún más pronunciado si fijamos la atención en los líderes del partido ${ }^{76}$; g) no resulta arriesgado afirmar que el partido ha alcanzado ya su techo electoral y que sus reivindicaciones autonómicas han sido sustancialmente satisfechas, pese a lo cual y ya en la nueva etapa, es harto improbable su desaparición, al menos a corto y medio plazo; h) cpera en una realidad social en la que no existe un movimiento nacionalista de carácter histórico con la suficiente consolidación y grado de vertebración interna, a diferencia de lo que ocurre en el País Vasco, Cataluña y, en menor medida, Galicia ${ }^{77}$; i) carencia de una base sociológica cobesionada como la que sin duda tienen Convergencia o el PNV, lo que vendría a dificultar su consolidación como partido; j) papel no especialmente apreciable del factor religioso entre las motivaciones de su electorado ${ }^{78}$, pese a las vinculaciones originarias de no pocos de sus dirigentes a movimientos católicos y en contraste también con la consideración tra-

is "Tierno es muy centralista; es de Soria y ejerce", declararía Rojas Marcos, contrastando esta postura con la buena disposición de Morodo (Andalán, marzo de 1979 , p. 3).

it "Ni ayer, ni hoy, ni mañana nos uniremos al PSOE. Esto sería traicionar al pueblo andaluz" (Rojas Marcos, julio 1979). De su biografía en Quién es quién en las Cortes Generales, cit.

" "La ese de socialista no la ejecuta ni la usa", escribe Eduardo Barrenechea en El País, antes de las autonomías (30-IV-1982). A título meramente indicativo véanse los datos que en el Informe FOESSA llevan a calificar a su electorado como de centro izquierda (pp. 570 y ss.).

is En el primer comité ejecutivo (abril 1977), compuesto por nueve miembros, hay cuatro abogados (uno de ellos empresario), un profesor adjunto de Universidad, un ingeniero, un perito, un representante de comercio y el último es un líder de USO-SAY, electricista de profesión, liberado por entonces.

${ }_{77} \mathrm{Cf}$. J. Rodríguez y E. Sevilla, cit., pp. 15-16.

78 De acuerdo con el Informe FOESSA, sólo una cuarta parte de sus votantes se declaraban practicantes o muy practicantes, aunque, si se suman los "no muy practicantes", los católicos suponen un 63 por 100 , porcentaje superior a los obtenidos para el PSOE y el PCE (59 por 100 y 34 por 100 , respectivamente) (pp. 571 y 572). 
dicional de la influencia de aquel factor en esta suerte de partidos, como ocurre en Irlanda del Norte, o en Euskadi con el PNV; k) perfecta compatibilidad entre la identidad regional y la española, es decir, no se cuestiona en ningún momento la lealtad a un Estado ya existente, a diferencia de lo que ocurre en algunas formaciones políticas del País Vasco o Cataluña y a semejanza, por ejemplo, de la situación en Gales o en Escocia: «cuando desde Andalucía se habla de autonomía y nacionalismo no se hace referencia a propósitos de secesión o separatismo... no se habla de independencia, sino de un camino para transformar nuestro secular esquema de dominio de clase" ${ }^{79}$. Esto es lo normal en una tierra donde, como recordaría Rojas Marcos en el debate de la moción de censura, no se usa la palabra «españolista», auténtico insulto para algunos en ciertas nacionalidades ${ }^{80}$. Sin lugar a dudas, transcurrida la primera etapa de la reforma política, tanto el regionalismo como el nacionalismo del PSA operaron dentro del sistema político, aceptando, «a pesar de todo», la Constitución ${ }^{81}$. Por otra parte, al tratarse de una región económicamente subdesarrollada, difícilmente este partido, o cualquier otro de signo nacionalista que surgiera en Andalucía, podría constituir una amenaza en términos territoriales. Lejos de ello, esa potencial amenaza se plantearía más bien en términos electorales, como así fue en el período 1979-1982; 1) el partido opera fundamentalmente en una región con clara identidad distintiva, es decir, existe un «hecho diferencial» andaluz, basado en factores étnicos que incluyen una cultura, tradición e historia propias, pero la lengua de ese territorio es sustancialmente la misma que la de la mayoría del país, aunque hava podido apuntarse la tesis de que Andalucía tiene «su propia expresión hablada", como manifestación de su identidad $^{82}$. En cualquier caso, no estará de más recordar que en casos tan nota-

79 Declaración del IV Congreso, pp. 30 y 31. Por su parte, el primer secretario general ya había subrayado esta posición del partido en sendas intervenciones del primer secretario del partido en el Congreso de los Diputados, correspondientes a la sesión de investidura de Suárez y al debate de la moción de censura: "La existencia del Estado del que formamos parte -orgullosamente formamos parte de él- nos exige una presencia en este foro" (DSC, núm. 3, 30-III-1979, p. 85). "A veces los nacionalistas defendemos al Estado español mejor que los centralistas...; los andalucistas tenemos muy claro qué es el andalucismo y siempre lo hemos unido al españolismo y al universalismo" (DSC, núm, 94, 29-V-1980, p. 6137).

${ }^{30}$ DSC, ibídem.

s1 Para la valoración que de ella hizo inicialmente el PSA, véanse: "A pesar de todo, sí a la Constitución", y "Comentario en torno a la Constitución", en Andalucía Libre (noviembre-diciembre 1978), pp. 1 y 7 . La Constitución se aceptó entonces como un "precio" que Andalucia habría que pagar por la democracia, "precio superior al de los pueblos desarrollados del Estado". Luego, con motivo de la moción de censura, se propondrá la reforma del Título VIII, que siempre se consideró "discriminatorio" (DSC, ibídem).

${ }^{82}$ Acosta se ha referido a la existencia de un habla distinta, producto de la transformación que el pueblo andaluz habría realizado transformando la lengua de otro conforme a su propia identidad cultural (Historia y cultura del pueblo andaluz, Barcelona, Anagrama, 1979, pp. 97-100). El grupo andalucista llegaría a defender, sin éxito, en la comisión constitucional correspondiente una enmienda al 
bles de nacionalismo como los de Escocia e Irlanda tampoco sería aplicable la tesis del carácter decisivo, en cuanto fuerza estructuradora, de las diferencias lingüísticas. Si éstas provocaron la primera ola de movilización regional, el reciente brote de regionalismo en Andalucía y otras partes de España, obedece más bien a discrepancias económicas: no en balde la redistribución de recursos económicos es el tema de nuestro tiempo, y no la de los recursos individuales como en el siglo $\mathrm{xIX}^{83} ; \mathrm{m}$ ) estamos ante el primer caso de un partido regional español que concurre, no sin cierto éxito, a unas elecciones en territorio distinto a aquel que le identifica (prescindiendo de EE que intentó lo propio en Madrid y Barcelona en 1979, el único paralelo posible, pero muy discutible, sería el de PNV y HB en Navarra): me refiero a la participación del PSA-Partido Andaluz en las autonómicas catalanas de 1980, en las que obtuvo un par de escaños. Este fenómeno, que tiene precedentes fuera de nuestras fronteras (por ejemplo. la búsqueda del voto en unas cuantas circunscripciones de Liverpool por los riacionalistas irlandeses) ha tenido su trascendencia política, evidenciando que el territorio es un concepto políticamente significativo y no neutral como ha sido presentado tradicionalmente $e^{84} ;$ y $n$ ) aunque, en la interpretación más optimista, el partido no remonta sus orígenes más allá de los años sesenta, probablemente no es casual que surja y prospere, siquiera sea transitoriamente, en un área geográfica que ha conocido históricamente numerosas manifestaciones de descontento popular: en efecto, el PSA iba a actuar fundamentalmente en un marco territorial en el que existen formas de expresión o manifestación del descontento político distintas a los partidos, formas que han alcanzado en épocas pasadas especial gravedad y que pudieran volver a plantearse con particular virulencia (me refiero, sobre todo, a las movilizaciones y revueltas campesinas). Pero en ese marco, a diferencia de lo que ocurre en el País Vasco, Francia o Italia, no juega ningún papel apreciable el fenómeno del terrorismo ${ }^{85}$. En todo caso, el PSA ha rechazado siempre explícitamente la violencia: desde su etapa como ASA, bajo el franquismo, se pronunció contra ella por considerarla "contrarrevolucionaria» para el momento ${ }^{86}$; y con motivo del debate sobre la moción de censura, su líder, Rojas Marcos, afirmaba: «Que se sepa que el pueblo andaluz ni ha utilizado ni útilizará jamás la violencia

proyecto de Estatuto de autonomia para Andalucía que hubiera supuesto la inclusión de una referencia explícita al "habla peculiar" andaluza y la obligatoriedad de su aceptación en la práctica oficial de los medios de comunicación", DSC, núm. 39 (29-VI-1981), pp. 1740 y ss.

${ }^{3}$ UrwIN, cit., pp. 352 y ss.

URWIN, cit., p. 349.

${ }^{85}$ La única manifestación de "lucha armada" desarrollada en los últimos años en Andalucia ha estado a cargo de los Grupos Armados Veintiocho de Febrero (GAVF-M28F) y limitada a Córdoba, causando sólo daños materiales (J. RoprfGUEz y E. SEviLL, cit., p. 22).

${ }^{26}$ Manifiesto fundacional de ASA, p. 100. 
en su lucha por la autonomía, y que los andalucistas estaremos en la vanguardia para conseguirlo» ${ }^{87}$.

\section{LA TRAYECTORIA ELECTORAL}

Cabe apuntar aquí la existencia de dos etapas diferenciadas: una primera, 1977-1979, de carácter ascendente para el partido, que alcanza su cenit en las legislativas de 1 de mayo y un éxito algo más moderado en las municipales del mes siguiente; y una segunda, iniciada prácticamente en noviembre de 1980 , con las elecciones parciales al Senado en Sevilla y Almería, acabando con sendos descalabrcs en las autonómicas y generales de 1982. Ambas etapas coinciden y contribuyen a fijar las que parecen dibujarse en la evolución electoral andaluza, según se ha puesto de relieve en un útil trabajo monográfico sobre el tema a cargo de los profesores Cazorla y Bonachela, para quienes las elecciones de 1979 constituirian un punto de inflexión entre ambas fases ${ }^{88}$.

\section{La carrera bacia el éxito: 1977-1979}

Como ya quedó dicho, el PSA recibe su bautismo electoral en los primeros comicios, a los que se presenta en coalición con el PSP, bajo las siglas US (Unidad Socialista). El cuadro adjunto recoge los sufragios obtenidos en Andalucía por la coalición en las candidaturas al Congreso, las cuales suponen un 4,7 por 100 del total de los votos válidos emitidos en la región, porcentaje sólo ligeramente superior al obtenido por US a nivel na. cional $(4,46$ por 100$)$. Lo primero que debe señalarse es la existencia de una relación directamente proporcional entre densidad de población e índice de votos obtenidos por la coalición en cada provincia: en efecto, los mayores índices corresponden a Cádiz - superando incluso al obtenido por el PSP en Madrid (9,15 por 100), aunque no al de la coalición en Zaragoza $(10,86$ por 100)-, Málaga y Sevilla, las tres provincias andaluzas de mayor densidad demográfica, no llegando al 3 por 100 en las tres de menor densidad (Jaén, Almería y Huelva), y cifrándose en un 3,6 por 100 en Granada y Córdoba, situadas en la zona intermedia. A esto se suma el hecho de que

${ }^{87}$ DSC, núm. 94, 29-V-1980, p. 6137. Recientemente, justificando "la necesidad de la existencia del Partido Andaluz", su secretario general, Luis Uruñuela, subrayaba en Tribuna Libre de El País el peligro de una "utilización del sentimiento de lo andaluz que... llegue a originar un nacionalismo violento", para presentar a su organización como abanderada del "verdadero nacionalismo andaluz... contra la violencia y contra cualquier desestabilización" (El andalucismo como factor de equilibrio, 26 junio 1984).

${ }_{88}$ "El proceso de constitución de la Comunidad Autónoma andaluza. Especial referencia a las elecciones de 23 de mayo y 28 de octubre de 1982 en Andalucia". comunicación presentada al III Congreso de la Asociación Española de Ciencia Política, Zaragoza, 24 al 26 de marzo de 1983, ejemplar multicopiado, p. 62. 
Evolución electoral del PSA en Andalucía. 1979-1982

\begin{tabular}{|c|c|c|c|c|c|c|c|c|c|c|}
\hline & \multirow{2}{*}{\multicolumn{2}{|c|}{$\frac{U S(P S A-P S P)}{1977 L}$}} & \multicolumn{8}{|c|}{ PSA-PA } \\
\hline & & & \multicolumn{2}{|c|}{$\begin{array}{c}1979 \mathrm{~L} \\
(1 \text { marzo })\end{array}$} & \multicolumn{2}{|c|}{$\begin{array}{c}1979 \mathrm{M} \\
(3 \quad \mathrm{abril})\end{array}$} & \multicolumn{2}{|c|}{$\begin{array}{c}1982 \mathrm{~A} \\
(23 \text { mayo })\end{array}$} & \multicolumn{2}{|c|}{$\begin{array}{c}1982 \mathrm{~L} \\
\text { (28 octubre) }\end{array}$} \\
\hline & Votos & $\%$ & Votos & $\%$ & Votos & $\%$ & Votos & $\%$ & Votos & $\%$ \\
\hline $\begin{array}{llllllllll}\text { Cádiz } & \ldots & \ldots & \ldots & \ldots & \ldots & \ldots & \ldots & \ldots & \ldots\end{array}$ & 40.843 & 9,6 & 81.598 & 19,3 & 48.616 & 13,3 & 35.407 & 9.20 & 16.654 & 3,44 \\
\hline $\begin{array}{lllllllll}\text { Sevilla } & \ldots & \ldots & \ldots & \ldots & \ldots & \ldots & \ldots & \ldots\end{array}$ & 33.629 & 4,9 & 101.601 & 14,5 & 82.177 & 13,1 & 37.348 & 5,60 & 23.375 & 2,93 \\
\hline $\begin{array}{lllllllll}\text { Málaga } & \ldots & \ldots & \ldots & \ldots & \ldots & \ldots & \ldots & \ldots\end{array}$ & 22.137 & 5,2 & 49.552 & 11,8 & 40.764 & 11,1 & 27.602 & 6,97 & 11.770 & 2,32 \\
\hline $\begin{array}{llllllll}\text { Córdoba } & \ldots & \ldots & \ldots & \ldots & \ldots & \ldots & \ldots\end{array}$ & 13.177 & 3,6 & 36.826 & 9,9 & 25.990 & 7,4 & 18.367 & 4,93 & 9.270 & 2,21 \\
\hline $\begin{array}{lllllllll}\text { Huelva } & \ldots & \ldots & \ldots & \ldots & \ldots & \ldots & \ldots & \ldots\end{array}$ & 5.037 & 2,5 & 17.720 & 9,5 & 11.566 & 6,8 & 7.241 & 4,18 & 3.752 & 1.71 \\
\hline $\begin{array}{lllllllll}\text { Granada } & \ldots & \ldots & \ldots & \ldots & \ldots & \ldots & \ldots & \ldots\end{array}$ & 12.665 & 3,6 & 22.136 & 6,1 & 23.132 & 7,0 & 9.985 & 2,86 & 4.939 & 1,22 \\
\hline $\begin{array}{llllllllll}\text { Jaén } & \ldots & \ldots & \ldots & \ldots & . . & \ldots & \ldots & \ldots & \ldots\end{array}$ & 6.488 & 2,0 & 11.335 & 3,4 & 6.828 & 2,2 & 11.544 & 3,49 & 4.750 & 1,31 \\
\hline $\begin{array}{lllllllll}\text { Almería } & \ldots & \ldots & \ldots & \ldots & \ldots & \ldots & \ldots & \ldots\end{array}$ & 5.225 & 2,9 & 5.074 & 2,8 & 5.755 & 3,5 & 6.214 & 3,85 & 2.558 & 1,24 \\
\hline Total Andalucia $\ldots \ldots \ldots$ & $\mathbf{j 3 9 . 2 0 1}$ & 4,7 & 325.842 & 10,9 & 244.828 & 9,1 & 153.709 & 5,42 & 77.068 & 2,20 \\
\hline
\end{tabular}


será en las ciudades y no en los pueblos donde Unidad Socialista halle mayor eco, por lo que su electorado puede considerarse fundamentalmente urbano. Aunque resulta imposible precisar en qué medida el voto era motivado por uno u otro partido, la circunstancia de que sean justamente Cádiz, Málaga y Sevilla las provincias donde el PSA ha_obtenido siempre mayor respaldo electoral hace pensar que el andalucismo yanó muchos más votos para la coalición que los que pudo aportarle la figura del profesor Tierno, pese a la amplia superposición del electorado potencial de ambas formaciones, entre el que predominaban las clases medias progresistas de las ciudades ${ }^{89}$.

En las elecciones generales de 1 de marzo de 1979, concurriendo en solitario, el PSA-PA duplicaría sobradamente los votos obtenidos por US en Andalucía veinte meses antes. Los más de 325.000 votos obtenidos por su candidatura al Congreso suponían casi el 11 por 100 de los sufragios andaluces y el 1,81 por 100 del conjunto del país; con ello, el partido pasaba a ser la cuarta fuerza electoral de la región, tras PSOE y UCD, y a poco más de dos puntos del Partido Comunista de Andalucía, y la sexta en número de votos a nivel nacional, por debajo sólo de los cuatro grandes partidos estatales y de Convergencia i Unió. Los anteriores porcentajes se traducirían, como es sabido, en cinco escaños en el Congreso, con lo que el partido se convertía en la séptima fuerza parlamentaria, inmediatamente detrás del PNV, $\mathrm{CiU}$ y AP (con siete, ocho y nueve diputados, respectivamente), y en la tercera fuerza regional de España. Los escaños correspondieron a las listas de Cádiz, Sevilla — dos en cada una- y Málaga - uno-, reflejando un mejor asentamiento del partido en esas provincias, circunstancia no alterada en toda su trayectoria (aunque ahora habría que hablar en términos de «menor debilidad", como poco). En el Senado no obtendrán escaño, pero su candidato más votado en Cádiz queda a poco más de 30.000 votos de los 114.445 alcanzados por el cuarto senador.

Ahora bien, está claro que, como ocurriera en 1977 con el voto de US, la distribución territorial del voto del PSA-PA no es precisamente homogénea: el desequilibrio es tal que el porcentaje que representan los sufragios obtenidos por el partido en la mitad de las provincias andaluzas - Cádiz, Sevilla, Málaga y Córdoba - sobre los obtenidos en la región es del 82,7 por 100. También es desigual el índice de incremento electoral respecto a los votos de US: así, éste casi se cuatriplica en Huelva, se triplica en Sevilla y prácticamente en Córdoba, mientras queda duplicado en Cádiz, y multiplicado por 1,7 en Granada y Jaéri, siendo nulo en Almería. Lo que sí hay es una subida generalizada del voto andalucista en términos absolutos en todas las provincias, excepto en la última citada, respecto a los votos obtenidos por US, circunstancia que no debe achacarse sólo a la ampliación del censo electoral con la incorporación de los jóvenes entre 18 y 21 años, pues aquélla, que equivale a un 15 por 100 aproximadamente para Andalucía, queda

Cf. A. Chrca, Las elecciones de 1977 en Andalucía, cit., pp. $42-43$. 
anulada en sus dos terceras partes por un incremento en diez puntos del índice de abstención. En cualquier caso, nadie discutirá que los resultados obtenidos en estas elecciones por el PSA.PA constituyeron un triunfo tremendo para un partido regional que nacía a la vida parlamentaria identificándose con una tierra que nunca en su historia contó con una fuerza política de este tipo en las Cortes. Baste pensar que una formación como $\mathrm{CiU}$, principal heredera de una rancia tradición política catalanista, sólo en una provincia - Geronasuperaba en porcentaje de votos al alcanzado por el PSA en Cádiz, mientras en otras dos - Lérida y Barcelona - sobrepasaba en poco más de un punto el porcentaje andalucista en Sevilla, quedando en la cuarta - Tarragonapor debajo de los índices del PSA en ambas provincias andaluzas ${ }^{90}$.

A mi entender, las razones que explican aquel éxito electoral guardan estrecha relación, entre otros, con los siguientes factores: a) una hábil utilización del argumento del agravio comparativo que habría sufrido Andalucía en el trato político y constitucional recibido en el tema autonómico, respecto a las llamadas nacionalidades históricas, trato del que se hace responsable a los partidos estatales «centralistas», en particular a la UCD y al PSOE, como principales protagonistas del consenso ${ }^{91}$. La incidencia de tal argumento tiene tanto más peso en cuanto que se hace en una tierra previamente abonada para ello, dada su situación de atraso económico respecto a la mayoría del país y la fuerte emigración humana y de capital, justamente hacia Cataluña y el País Vasco, las regiones que se considera han salido beneficiadas en la solución arbitrada para la cuestión autonómica; b) el desgaste experimentado por el PSOE en Andalucía, consecuencia de haber desempeñado la presidencia de su órgano preautonómico en el marco de un creciente proceso de frustración en las reivindicaciones de este signo ${ }^{92}$, pero fruto también de algunos «deslices» dialécticos protagonizados por dirigentes socialistas, como el ya mencionado del diputado y miembro de la Ejecutiva, Mújica Herzog, o el del primer presidente de la Junta de Andalucía, Plácido Fernández Viagas ${ }^{93}$, errores políticos -cuando menos,

"Véanse el mapa y cuadro de implantación de los distintos partidos regionales, en J. de Esteran y L. López GuERra, Las elecciones legislativas de 1979, cit., pp. 493-494.

"Tanto la UCD como el PSOE vieron descender su porcentaje global de voto en Andalucía respecto a 1977 en 2,7 y 2,1 puntos respectivamente, mientras ven aumentado su respaldo electoral PSA, PCA y la extrema izquierda, por este orden. El PSOE retrocedía en la mitad de las provincias andaluzas, coincidentes con cuatro de las cinco en que el PSA ganaba mayor terreno, mientras la quinta - Huelva, donde el PSOE avanzaba ligeramente- era escenario del mayor retroceso de la UCD (para estos datos y su detalle por provincias y partidos, véase J. Cazorla y M. Bonachera, cit., cuadro 5).

${ }^{2}$ Para esta opinión, hecha extensible al País Vasco, véase J. M. Maravall, Sistema, núm. 36 (mayo 1980), p. 98.

${ }^{93}$ Fernández Viagas, poco antes de alcanzar la presidencia de la Junta, declararía a la prensa que no sólo no era andalucista, sino que incluso le molestaba la palabra andalucismo, expresando sus dudas sobre la existencia de un país andaluz (Ideal, de Granada, 21 mayo 1978). 
de diplomacia - que serían convenientemente aireados por los nacionalistas andaluces ${ }^{34}$. Por el contrario, el PSA-PA, marginado tanto por la Junta como por la Comisión Permanente y el pleno de la asamblea de parlamentarios, que él contribuyó a hacer posible, en todo el proceso de elaboración del proyecto de preautonomía, había acrecentado su capital político en ese período ${ }^{95}$; c) las secuelas del consenso, que beneficiaron más a terceros partidos, en especial la gran mayoría de los regionales, incluido el PSA, que a sus grandes artífices ${ }^{\%}$; d) la incorporación al censo electoral de una gran cantidad de jóvenes, entre los que tuvo cierto impacto el ideario andalucista; e) la doble imagen con que el partido se presentó ante el electorado, conservando la «S» de socialista en sus siglas, pero subrayando con todas sus letras lo de Partido Andaluz, pienso que le hizo ganar no pocos votos en esta convocatoria entre el electorado no socialista (un indicio de ello podría ser el hecho de que el partido suba puntos respecto a 1977 en provincias como Huelva y Granada, donde, aunque el PSOE y el PCE también los ganan ligeramente, desciende acentuadamente la UCD y, en menor medida, AP); y f) «last but not least», una campaña electoral dotada de medios económicos en un grado en el que nunca, ni siquiera en las autonómicas, volvería a disponer el partido andalucista.

El saldo arrojado por las legislativas llevó a que desde la prensa del partido se especulase con la tentadora idea de su «irresistible ascensión»: la confirmación de ésta en las municipales se daba como "previsible» ${ }^{9}$. Pero los nuevos resultados, siendo buenos y aun espectaculares en algún caso, evidenciaron que aquélla podía ser frenada. El PSA, que presentó 91 candidaturas, con las que abarcaba el 80 por 100 del electorado, perdió algo más de 80.000 votos y 1,8 puntos en el porcentaje de los obtenidos, respecto

94 Puede citarse como muestra el artículo firmado por Pedro Ruiz Morcillo, a la sazón miembro del comité ejecutivo del PSA, con el título "El señor presidente", en el que, entre otras cosas, se lee lo siguiente: "¿Es Tarradellas catalanista? ¿Cree Ramón Rubial en la existencia de Euskadi? La sóla formulación de estas preguntas es absurda, y, en cualquier caso, si a alguno de los dos se le hubiera ocurrido una respuesta semejante a la del señor Fernández Viagas, el escándalo político hubiese sido de los que hacen época... No ha bastado que un millón y medio de andaluces salgan a la calle para que los políticos que los representan se decidan de una vez por todas a mirar las cosas desde Andalucía y no desde Madrid... Para esa cosa que se llama pueblo andaluz las palabras de Fernández Viagas constituyen, a nuestro entender, una ofensa" (Ideal, de Granada, 30 mayo 1978).

95 Rojas Marcos se quejaría del "menosprecio" hacia su partido por parte de estos órganos recordando que las candidaturas de US tuvieron en Andalucía más de doscientos mil votos y manifestando que en otras regiones (Galicia, por ejemplo) se habia seguido otra conducta con los partidos extraparlamentarios y que el PCE, a pesar de tener esta condición, sí había sido tenido en cuenta (El Europeo, 24 enero 1978 , p. 36).

* La UCD sube tan sólo unas décimas respecto a 1977, mientras que PSOE y PCE ganan poco más de un punto.

97 "El PSA en las elecciones municipales", Andalucía Libre, núm. 12 (marzo 1979), p. 5. 
a la anterior convocatoria. Con todo, no puede hablarse de un retroceso significativo en ese momento, pues hay que tener en cuenta un par de factores: primero, el incremento de la abstención $-6,4$ puntos para Andalucía-, que por sí sólo representaba más de la cuarta parte de los votos perdidos, y segundo, la peculiar naturaleza de las elecciones locales, que perjudica a los partidos de menor tradición y con implantación territorial desequilibrada, circunstancias concurrentes en el caso ${ }^{\text {y8 }}$. Por otra parte, los profesores Cazorla y Bonachela, analizando la evolución electoral del PSA entre los dos comicios de 1979, han hecho notar que, aunque el partido experimenta un descenso general en su porcentaje de votos en las distintas provincias, salvo en las de Granada y Almería (en ambas registra incluso un aumento en el número de sufragios), en todas ellas, a excepción de Cádiz, existe por lo menos una comarca en la que aquél experimenta una subida progresiva de votos, extensible a las primeras elecciones. En alguna medida, esto podría interpretarse como un signo de vitalidad y pujanza, si bien el hecho de que la excepción sea justamente Cádiz - la provincia donde siempre obtuvo los mejores resultados - sugiere que los andalucistas habrían tocado techo. Lo que sí es cierto es que los resultados globales estuvieron por debajo de las previsiones hechas desde la prensa del partido ${ }^{\%}$, aunque en el marco de los pactos municipales de la izquierda éste consiguiera alcaldías como las de Sevilla, Jerez, San Fernando, Ecija, Ronda, Coín, Isla Cristina, Archidona o Alhama de Granada, totalizando 283 concejales ${ }^{100}$, de ellos una gran parte en ciudades de más de 15.000 habitantes.

\section{Del deteriorc al desastre: 1980-1982}

Desde el momento en que prestó su apoyo a Suárez en la investidura, el PSA comenzaba a gastar, cuando no a derrochar, el capital político acumulado hasta entonces. Es verdad que esa decisión no pudo dañarle gran cosa

\%* Al margen de la imposibilidad manifiesta de presentar candidaturas en muchos municipios pequeños, en algunos comités provinciales, como el de Granada, parece que pesó la consideración de que no se debía concurrir allí donde no hubiera candidatos de suficiente confianza para el partido, al objeto de evitar la avalancha de "convertidos" al andalucismo. Málaga sería el ejemplo de la opción contraria (presentarse en todos los sitios donde hubiese gente dispuesta a ello), registrándose sólo un ligerísimo descenso con el índice de votos, a diferencia de lo que ocurrió en Cádiz y Sevilla, las otras dos provincias en que el PSA tenía mejor implantación. (A este respecto, resulta sintomático que de los cuatro concejales andalucistas en la capital malagueña, dos se pasaran al PSOE poco antes de las municipales, barajándose su inclusión en puestos destacados de la lista socialista. $A B C, 5$ febrero 1983.)

99 De un total de 23 pueblos concretos de los que se daban como "muy probables" en cuanto a contar con alcaldes andalucistas en la primavera, sólo en siete su lista fue la más votada. "El PSA en las elecciones municipales", ibidem.

${ }_{100}$ El País, 29-IV-1983. Andalucía Libre da la cifra de 279 concejales (núm. 14, abril de 1979, p. 3). 
en las municipales, pues aquellos partidos con quienes se disputaba el electorado, en particular el PSOE, apenas si tuvieron tiempo de utilizarla como arma política, ya que quedaban tan sólo un par de días para cerrar la campaña, y además, la UCD de entonces mantenía sustancialmente su imagen y fuerza electoral en Andalucía, a casi diez meses de que iniciara la «reconducción» del proceso autonómico, con el subsiguiente embarque en el absurdo planteamiento abstencionista del referéndum andaluz. Pero aquella estrategia de negociaciones y pactos a derecha e izquierda según sus hombres accedían al Parlamento y a los municipios, acentuada al año siguiente con el vaivén político que suponía votar en el mismo sentido afirmativo, mediando poco más de tres meses, la moción de censura y la cuestión de confianza, terminaría teniendo un alto costo electoral para el partido andalucista en las autonómicas y en las legislativas de 1982. Mientras tanto el PSA había concurrido a las elecciones al Parlamento catalán y a las parciales para cubrir un par de vacantes al Senado en Almería y otra en Sevilla.

En las primeras, celebradas en marzo de 1980, a tres semanas del 28-F, el PSA obtuvo un par de escaños por Barcelona, con el 3,03 por 100 de los votos emitidos en la provincia y el 2,66 por 100 de los emitidos en Cataluña, lo que suponía algo más de 72.000 sufragios. Los resultados, pese al éxito parlamentario, distaban no poco de las expectativas de un partido que se presentaba con la aspiración de representar a todos los emigrantes andaluces en Cataluña ${ }^{101}$. Mayor significación para nuestro análisis tienen las mencionadas elecciones parciales de noviembre de ese año. El momento es precisamente lo que da a éstas su importancia política, pues, en cierto modo, permitía interpretar los resultados como una manifestación de la opinión andaluza respecto a la política autonómica de los partidos políticos que competían por su voto, en los nueve meses transcurridos desde el referéndum. Como ya se dijo, el PSA, en especial su líder, Rojas Marcos, había puesto grandes esperanzas en el candidato andalucista por Sevilla, pues su triunfo, e incluso el mantener las posiciones, habría podido ser presentado ante los disidentes como un respaldo popular a la estrategia desplegada durante ese verano por el secretario general, negociando con la UCD el desbloqueo del proceso autonómico por la vía del 144 . Pero el hecho es que el partido salió seriamente dañado de estas elecciones al perder 63.805 votos en la provincia, respecto a los 115.601 obtenidos por su candidato más votado en 1979 , y verse casi duplicado y cuatriplicado en sufragios por los candidatos del PCA y del PSOE, respectivamente, cuando en aquella ocasión el primero sólo le sobrepasaba ligeramente, mientras el segundo no alcanzó a duplicarle.

Frente a esto, el que en Almería el candidato andalucista más votado

${ }^{101}$ Este electorado potencial de población inmigrada ha sido estimado en un 40 por 100 de los catalanes. Los mejores resultados andalucistas a nivel comarcal -en torno al 4 por 100 de los votos- correspondían a comarcas urbanizadas y de elevada industrialización. Equipo de Sociología Electoral, "Las elecciones catalanas del 20 de marzo de 1980", REP, núm. 14 (marzo-abril 1880), pp. 195 y ss. 
ganase cerca de 4.000 votos respecto a 1979 , pese al sensible descenso de la participación -que también bajó en Sevilla-, carecía de trascendencia. Más aún cuando el PSOE, aun perdiendo sufragios, se hizo con los dos escaños que antes ocupara una UCD cuyos candidatos todavía triplicaban en sufragios a los andalucistas ${ }^{102}$. Como se recordará, poco después se celebraba el Congreso extraordinario, que intentaría inútilmente zanjar la crisis con la expulsión de los «fraccionalistas». Que la crisis es puesta implícitamente en relación no sólo con los problemas internos del partido, sino con el fracaso en las recientes elecciones parciales, lo evidencia el hecho de que $A n$ dalucía Libre, en su edición de febrero, trate como cuestiones diferenciales la «crisis del PSA» y la "crisis del andalucismo político», tema sobre el que recoge un amplio debate en el que no faltan referencias a la fragilidad de la conciencia nacionalista andaluza y a la invasión del terreno político andalucista por el PSOE.

Por razones obvias, las elecciones al Parlamento andaluz, en mayo de 1982, constituían la gran prueba para el PSA: ésta era su oportunidad de demostrar no sólo a la opinión pública y a los partidos «centralistas», sino a sus propios militantes que los anteriores comicios no fueron otra cosa que un simple episodio electoral sin mayores consecuencias y que el partido había superado la grave crisis interna abierta una veintena de meses atrás, de modo que ésta sería ya simplemente parte de la historia del partido. En principio, éste tenía a su favor en la campaña la exclusividad en la oferta nacionalista, dado que el partido de Clavero, Unidad Andaluza, decidió no competir en las elecciones: aunque rechazada por amplios sectores, dicha oferta parecía gozar de un cierto eco popular. Además, se le había unido el antiguo PTE-PTA y, lo que es más importante, contaba con el apoyo explícito de los líderes de los jornaleros andaluces (Francisco Casero, secretario general del SOC, entre ellos). Sin embargo, el revés electoral, calificado de «incomprensible y desconcertante» desde las páginas de Andalucía Libre ${ }^{103}$, fue mayúsculo: el PSA, al que las encuestas situaban por encima del 10 por 100 de los votos y entre la segunda y la cuarta posición ${ }^{104}$, pasaba de la cuarta a la quinta y no llegaba al 5,5 por 100 de sufragios, perdiendo 172.000 , aproximadamente, respecto a las legislativas de 1979 (pese a que la abstención sólo subió un par de puntos) y descendiendo casi a los niveles de 1977. La pérdida de votos es generalizada, salvo en las provincias donde sus re-

${ }_{102}$ Cf. Fernando OLLERo, "Elecciones parciales al Senado en Almería y Sevilla", Revista Departamento Derecho Político, núm. 9 (primavera 1981), pp. 211-215.

${ }^{103}$ Editorial núm. 48 (junio 1982).

${ }^{10+}$ Las encuestas aludidas por fuentes andalucistas le situaban nada más que en segunda posición. Andalucía Libre, núm. 47 (mayo 1982), p. 2. También algunos sondeos de primeros de marzo citados por El País. Las encuestas realizadas por los empresarios y conocidas a comienzos de mayo le colocaban en tercera posición, con un 14 por 100 de los votos, tras PSOE y UCD. Por último, el sondeo de Sofemasa, realizado del 8 al 11 de mayo, se aproximaba más a la realidad al situarle en cuarta posición, pero le otorgaba un 11,5 por 100 de sufragios, con un 6,4 por 100 de voto decidido (El País, 11 y 16 mayo 1982). 
sultados habín sido siempre más pobres, Jaén y Almería, que ahora registran algún incremento en relación a las últimas legislativas. En términos proporcionales, el retroceso mayor es el experimentado en Sevilla, que pasa de la segunda a la tercera posición en índice de votos andalucistas, a la que siguen Huelva, Granada, Cádiz y Córdoba, por este orden, siendo Málaga la menos afectada. Respecto a las municipales, y en los mismos términos, será en Granada, seguida de Sevilla y Huelva, donde las pérdidas sean más acentuadas. Como puede verse, en ambos casos el mayor desastre se vive en Sevilla - cuya capital es cuna y sede oficial del partido, al tiempo que testigo privilegiado de sus interioridades-y en las provincias cuyas capitales vieron canjeadas sus alcaldías por la de aquélla.

Aunque se logra superar el 5 por 100 de los sufragios y el partido ob. tiene un escaño en las provincias de Cádiz, Málaga y Sevilla, los resultados eran difícilmente asumibles por un partido que, al fin y al cabo, había sido el promotor originario del proceso autonómico en el que se enmarcaban esas elecciones; y que todavía en febrero de 1982, en la introducción a su programa electoral, afirmaba su vocación de partido hegemónico, objetivo que da por seguro que alcanzará. Piénsese que los tres escaños equivalen tan sólo al 2,7 por 100 de la Cámara, con lo que la representación andalucista en ella era poco mayor que la obtenida en el Parlamento catalán. Con todo, ello significa que, aunque bastante apagado, el partido ampliaba su presencia institucional a un nuevo ámbito. Por esto, los resultados de las últimas legislativas, en las que se aspira a conseguir nada menos que 15 diputados ${ }^{105}$, casi hicieron buenos los de las autonómicas. Como es sabido, desde octubre los andalucistas desaparecen del Congreso de los Diputados, obteniendo sus listas tan sólo el 2,2 por 100 de los sufragios emitidos en Andalucía, con lo que se da la paradoja de que el partido - que tan sólo en la provincia de Cádiz superó el 3 por 100 - conseguía menos respaldo en la tierra que le identifica que el que encontró en Cataluña dos años antes. Así pues, estas elecciones tenían como consecuencia el inicio del repliegue andalucista de las instituciones, repliegue acentuado en las últimas elecciones municipales, donde el partido pierde casi la mitad de los concejales que obtuvo cuatro años antes y todas las alcaldías de pueblos y ciudades importantes, a excepción de las de Jerez y Ecija, y de la de San Fernando, donde empata a concejales con el PSOE ${ }^{106}$. Sumamente ilustrativo de este declive resulta el hecho de que ni uno sólo de los ayuntamientos de las ocho capitales andaluzas cuente entre sus concejales con algún candidato del PSA-PA, cuando,

10s Andalucia Libre, núm. 50 (octubre 1982), pp. 2 y 8.

106 Datos extraídos de El Pais, 10 de mayo de 1983. El resto de alcaldes del PSA hasta un total de 11, corresponden a Torrox, Frigiliana y Canillas de la Sierra (Málaga), Iznajar y Palenciana (Córdoba), Paterna de la Rivera (Cádiz), La Lentejuela (Sevilla) y María (Almería). Fuente: Anuario El País, 1984. 
en 1979, éstos sumaban 40, con un mínimo de tres ediles en cada una de aquellas corporaciones ${ }^{107}$.

Pienso que los estrepitosos fracasos electorales experimentados por el PSA en las elecciones de 1982, así como el más moderado de las parciales al Senado por Sevilla, obedecen en gran parte a un cúmulo de errores propios, hábilmente capitalizados por su principal rival electoral, el PSOE. Entre tales desaciertos, cabe destacar: los dos votos a Suárez, su constante obsesión contra el PSOE (de lo que tampoco es ajeno este partido, consciente de que en un duelo con el PSA éste no tiene nada que hacer y lo aprovecha...) ${ }^{100}$, el trueque de las alcaldías de Granada y Huelva por la de Sevilla, la apuesta por el artículo $144 \mathrm{y}$, en general, la política ambigua, de chalaneo y pactos a destiempo (el PSOE acertó a hacerlos en su momento sin mayores costos), tremendamente personalista, de su líder Rojas Marcos, quien ofrecía un blanco fácil a las críticas, que a su vez lo eran al partido. Todo ello desconcertó no ya a quienes le habían votado antes, sino a sus propios militantes y dirigentes, generando una profunda crisis interna, con su secuela de sanciones y expulsiones, que deterioró aún más la imagen del partido. Uno de sus altos mandatarios describía la situación en términos bien expresivos: «Hemos estado poniéndole balones al contrario para que los rematara a placer» ${ }^{109}$. Al margen de airear aquellos pactos, ambigüedades y contradicciones, el PSOE, y en particular Rafael Escuredo desde que sucediera a Fernández Viagas al frente de la Junta, tuvo el gran acierto de, como expresara Vázquez Montalbán en frase no menos gráfica, «vampirizar el andalucismo del PSA hasta dejarlo casi sin sangre» ${ }^{110}$. Con ello, el PSA veía

${ }^{107}$ Pese a tan pobres resultados, el Comité Nacional del PSA hacía público un comunicado en el que aquéllos eran valorados positivamente en cuanto "notable recuperación respecto a las últimas elecciones generales" (El País, 11 mayo 1983). Es cierto que el PSA es de los pocos partidos que ven aumentados sus votos respecto a las legislativas del 28 de octubre -el único junto al PCE y el PNV que obtiene unos pocos sufragios adicionales (5.000 más) -, al pasar de 77.000 a más de 110.000 ; pero hay que tener en cuenta que la mitad de estos votos corresponden a la provincia de Cádiz y, de ellos, la gran mayoría a Jerez de la Frontera, donde la imagen de su alcalde -Pedro Pacheco- contó mucho más que la del propio partido: la candidatura por él encabezada obtuvo 39.231 votos, lo que representaba el 53,9 por 100 de los sufragios expresados, cuando en las últimas elecciones generales el voto PSA en Jerez significó únicamente el 6,5 por 100, sumando en toda la provincia de Cádiz tan sólo 15.593 sufragios (El Pais, 9 noviembre 1982, y 8 y 13 mayo 1983 ).

${ }^{108}$ Andalucía Libre, núm. 48 (junio 1982), p. 8.

${ }^{109}$ El País, 17 de octubre de 1982.

110 El Pais, 8 de junio de 1982. Además, Escuredo incorporó a la Junta de Andalucía, en calidad de consejeros presidenciales, a varios ex dirigentes del PSA, como Francisco Torres, José Antonio Sainz Pardo y José Antonio Sánchez, ofreciendo incluso una consejería al propio Emilio Pérez Ruiz siendo éste todavía diputado andalucista por Sevilla, lo que fue interpretado como una voluntad de fagocitar totalmente al PSA (El País, 17 de octubre de 1982). El ex dirigente nacionalista asesoraría a Escuredo en temas económicos y, al igual que Sainz Pardo y Sánchez - jefe del gabinete de asesores de la presidencia de la Junta y responsable de política informática, respectivamente-, no tardó en solicitar el ingreso 
mermado sustancialmente su espacio político, pues, si en 1977 iba como una opción socialista más y en 1979 como «la opción andalucista», en posteriores ocasiones esta opción se la estaba disputando con el PSOE de Andalucía, que contaba con un Escuredo convertido en nuevo adalid del andalucismo $y$, aunque en menor medida, con el PCA.

Por otra parte, el PSA equivocaba los términos de la confrontación al plantear ésta como un enfrentamiento centralismo-andalucismo por encima del antagonismo derecha-izquierda, aunque acaso no tuviera otra alternativa, pues de lo contrario hubiera sido problemático diferenciar su oferta electoral de la del PSOE.

A los anteriores factores, se suma la pérdida de protagonismo del PSA en la defensa de la autonomía andaluza, algo reconocido por su propia de. claración del IV Congreso (junio de 1981). Y la mengua de los recursos financieros, que coincide cronológicamente con su distanciamiento de la UCD de Calvo Sotelo al votar en contra de este último en la investidura tras un debate que enfrentó al candidato y a Rojas Marcos en términos bastante agrios ${ }^{111}$, merma que ha llegado a límites extremos en las dos últimas campañas electorales ${ }^{112}$. Según todos los indicios, el ahora Partido Andalucista no tiene ante sí un futuro inmediato excesivamente brillante. Sin embargo, existen serias dudas de que ello signifique simplemente que estamos ante los lógicos efectos de la curación de un supuesto sarampión regionalista. En cualquier caso, habría mediado la aplicación de un serio tratamiento que incluiría la asunción a nivel político de esa índole de sentimientos por parte del partido hoy mayoritario y la satisfacción formal del nivel de aspiraciones autonómicas del pueblo andaluz, en el marco de una situación forzada por la incesante actividad de un partido «molesto», el PSA.

En última instancia, viendo el problema desde una perspectiva distinta, lo que importa no es tanto que este partido regional sea grande o pequeño, se consolide o desaparezca, como la resolución de las quejas de un pueblo, que son las que podrían explicar el efímero éxito electoral de aquél y su hipotético resurgir en el panorama político andaluz y español.

en el PSOE de Andalucía (las tres solicitudes iban avaladas por Escuredo y Rodriguez de la Borbolla, lo que no evitó algunas reticencias en un sector socialista tradicional).

"11 Véase DSC, núm. 144 (19 febrero 1981), pp. 9168-9169.

112 La penuria de medios materiales de propaganda, reducidos a poco más que banderolas y carteles, ha sido nota destacada por la prensa en ambas ocasiones (véase El Pais, 17 octubre 182 y 29 abril 1983). Sin duda la economía del partido debió quedar maltrecha tras el infructuoso esfuerzo realizado en las elecciones al Parlamento andaluz, con un presupuesto cifrado por su secretario en 70 millones de pesetas, muy lejos con todo de Ios 224 millones gastados por el PSOE en esa decisiva campaña (datos recogidos en El País, 3 y 23 mayo 1982). 